\title{
Intramolecular glycosylation
}

\author{
Xiao G. Jia and Alexei V. Demchenko*
}

\author{
Review \\ Address: \\ Department of Chemistry and Biochemistry, University of Missouri - \\ St. Louis, One University Blvd., 434 Benton Hall (MC27), St. Louis, \\ MO 63121, USA \\ Email: \\ Alexei V. Demchenko* - demchenkoa@umsl.edu \\ * Corresponding author \\ Keywords: \\ carbohydrates; glycosylation; intramolecular reactions; \\ oligosaccharides
}

Beilstein J. Org. Chem. 2017, 13, 2028-2048.

doi:10.3762/bjoc. 13.201

Received: 04 May 2017

Accepted: 13 September 2017

Published: 29 September 2017

This article is part of the Thematic Series "The glycosciences".

Guest Editor: A. Hoffmann-Röder

(C) 2017 Jia and Demchenko; licensee Beilstein-Institut. License and terms: see end of document.

\begin{abstract}
Carbohydrate oligomers remain challenging targets for chemists due to the requirement for elaborate protecting and leaving group manipulations, functionalization, tedious purification, and sophisticated characterization. Achieving high stereocontrol in glycosylation reactions is arguably the major hurdle that chemists experience. This review article overviews methods for intramolecular glycosylation reactions wherein the facial stereoselectivity is achieved by tethering of the glycosyl donor and acceptor counterparts.
\end{abstract}

\section{Introduction}

With recent advances in glycomics [1,2], we now know that half of the proteins in the human body are glycosylated [3], and cells display a multitude of glycostructures [4]. Since glycan and glycoconjugate biomarkers are present in all body fluids, they offer a fantastic opportunity for diagnostics. Changes in the level of glycans, as well as changes in glycosylation and branching patterns, can indicate the presence and progression of a disease [5-9]. With a better understanding of functions of carbohydrates, the quest for reliable synthetic methods has launched, thus elevating the priority for improving our synthetic competences. The development of new methods for stereocontrolled glycosylation [10-14] in application to the expeditious synthesis of oligosaccharides represents a vibrant worldwide effort [15-32]. Nevertheless, despite extensive studies that have emerged since the very first experiments performed by
Arthur Michael and Emil Fischer in the late 1800's, the glycosylation reaction remains challenging to chemists.

Enzymatic glycosylation reactions are highly stereoselective [33]. However, the stereocontrol of chemical glycosylation reactions remains cumbersome despite of significant advances. Common intermolecular glycosylation reactions in the absence of a participating auxiliary typically proceed with poor stereoselectivity. In these systems, there are no forces that are able to direct the glycosyl acceptor attack on the activated glycosyl donor that exists as a flattened oxacarbenium intermediate (Scheme 1a). Early attempts to achieve some stereocontrol of glycosylations were mainly dedicated to the development of participating groups and optimization of the reaction conditions. More recently, the research emphasis is switching towards 


\section{A. Intermolecular glycosylation}

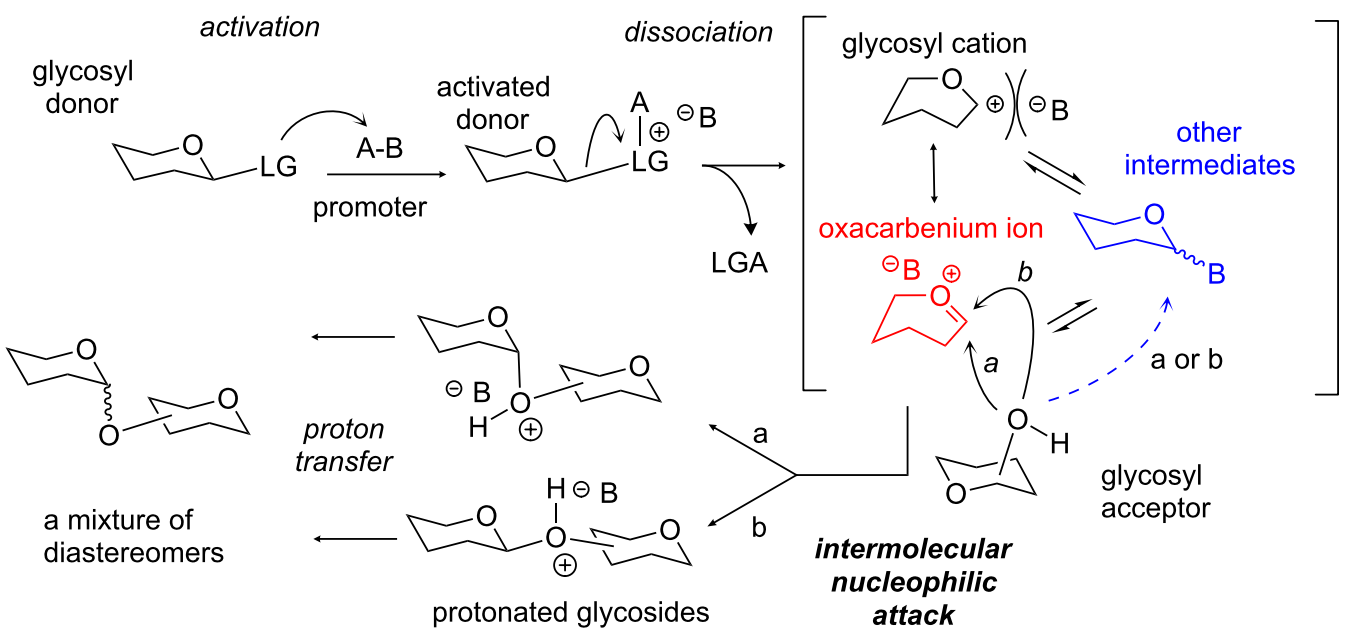

\section{B. Intramolecular glycosylation}

glycosyl donor

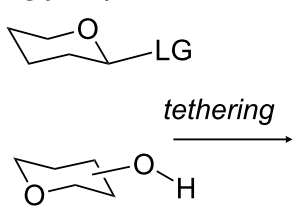

glycosyl acceptor

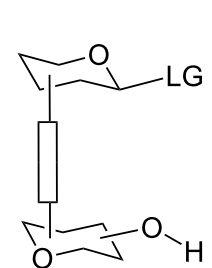

activation

$\mathrm{O}-\mathrm{J}^{-}$ dissociation

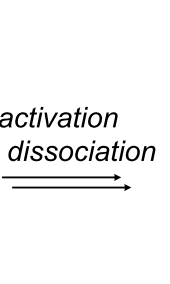

intramolecular nucleophilic attack proton transfer tether removal

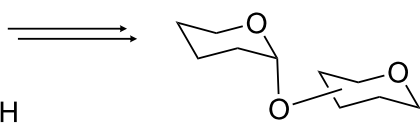

$1, \mathrm{X}$-syn glycoside in respect to the tether

Scheme 1: The mechanistic outline of the intermolecular (a) and intramolecular (b) glycosylation reactions.

understanding of other, more fundamental factors and aspects of glycosylation. Extensive studies dedicated to conformation, configuration, stereoelectronics of the starting material, and key reaction intermediates have emerged [34-37].

Beside these attempts, an area of the intramolecular glycosylation has also been developed with an idea of providing higher efficiency of glycosylation reactions by bringing the reaction counterparts in a close proximity to each other. In many variations of this general concept, the intramolecular approach also allows for achieving better stereocontrol in comparison to that of an intermolecular reaction. This is usually credited to the facial selectivity for the glycosyl acceptor attack restricted by the tethering (Scheme 1b). However, the execution of this concept requires additional steps for the preparation of the tethered donor-acceptor combinations, and in some cases postglycosylational modifications are also required. As a result, glycosylation that is already a four-step process (activation, dissociation, nucleophilic attack, proton transfer, Scheme 1a) has to be supplemented with additional manipulations that could lead to the decrease in over-all efficiency and yields. Hence, intramolecular glycosylations have a particular relevance to special cases of glycosylation or particularly challenging targets, such as 1,2-cis glycosides, where other, more direct methods fail to provide acceptable results.

Presented herein is an overview of methods that have been developed to achieve higher efficiency and/or better stereoselection by tethering the donor and acceptor counterparts, reactions that are commonly referred to as intramolecular glycosylations. A number of approaches for connecting the reaction counterparts, glycosyl donor and acceptor together, have been developed to provide the enhanced facial selectivity for the acceptor attack [38-41]. Beyond early intramolecular glycosylations achieved via the orthoester rearrangement by Lindberg [42] and Kochetkov [43], as well as the decarboxylation of glycosyl carbonates by Ishido [44], Barresi and Hindsgaul [45] are often credited for the invention of the intramolecular glycosylation in 1991. However, it is a pioneering albeit less known research by Kusumoto et al. in 1986 [46] that actually started the developments in this area. Of this general idea for the intramolecular glycosylation, three different concepts have been invented: a "molecular clamp" approach, intramolecular aglycone delivery (IAD), and leaving group-based methods (approaches A-C, Figure 1). This review will discuss recent developments in the field of intramolecular glycosylations with the 


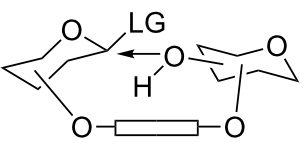

A. "molecular clamp" concept

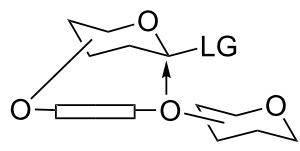

B. intramolecular aglycone delivery

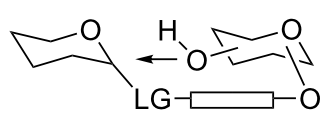

C. leaving group-based methods

Figure 1: Three general concepts for intramolecular glycosylation reactions.

main emphasis on the developments of the past decade. A similar overview, albeit with the emphasis on molecular clamping, was presented as an introduction to the doctoral dissertation by Jia [47]. For previous developments in this area the reader should refer to a number of comprehensive overviews of intramolecular glycosylations in general [38-40] and IAD in particu$\operatorname{lar}[41,48-50]$.

\section{Review}

\section{Molecular clamping method Early developments}

The "molecular clamp" concept (approach A, Figure 1) represents the first general concept for a intramolecular glycosylation strategy. The attachment of the glycosyl donor and acceptor via a tether takes place away from the reactive centers. These attachment strategies clearly distinguish the molecular clamp method from other intramolecular concepts wherein the attachment involves one of the reactive sites, acceptor hydroxy group in IAD or the leaving group of the donor. "Molecular clamping" was introduced by Kusumoto et al. [46], however, this term was coined by the same group much later [51]. We adopt this term to generally refer to this concept, which in other applications was also named "intramolecular glycosylation of prearranged glycosides" by Ziegler [52,53], "template-directed cyclo-glycosylation" by Valverde et al. [54], "remote glycosidation" by Takahashi [55] and "templated oligosaccharide synthesis" by Demchenko [56].
Initially introduced by Kusumoto et al. in 1986 [46], the molecular clamping clearly demonstrated the advantages that intramolecular glycosylations can offer. The first attempt to obtain a target disaccharide quipped with muramic acid from donor $\mathbf{1}$ and acceptor $\mathbf{2}$ failed (Scheme 2). The authors rationalized that "... a novel device was required to facilitate the coupling. We thus tried to connect the two components prior to the glycosidation reaction with an ester linkage which can be formed more readily than a glycosidic bond. ... The glycosylation reaction then becomes an intramolecular process and hence could be expected to proceed more easily." The authors then refer to a known phenomenon in the field of peptide chemistry "where two components to be coupled had been brought close together by auxiliary groups."

With this general idea in mind, and after "examination of molecular models" the authors created compound 3 that was tethered via the muramic acid moiety to the C-6 position of the donor that in their opinion was "sterically most favorable for the formation of $\beta(1 \rightarrow 4)$ glycoside." Indeed, after sequential glycosylation in the presence of $\mathrm{TsOH}$ at $50{ }^{\circ} \mathrm{C}$, methanolysis, and per-acetylation, disaccharide 4 was isolated in $20 \%$ yield. The authors then very reasonably concluded that "Consequently, the presence of the ester linkage which kept the two sugar moieties in close proximity to each other certainly favored the formation of the desired glycoside bond in the above experiment. Thus, this is the first example of the so-called

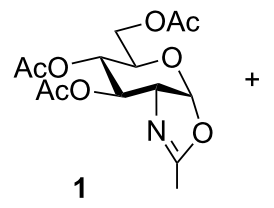

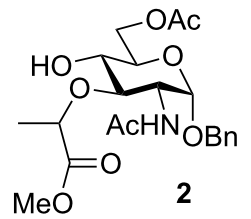
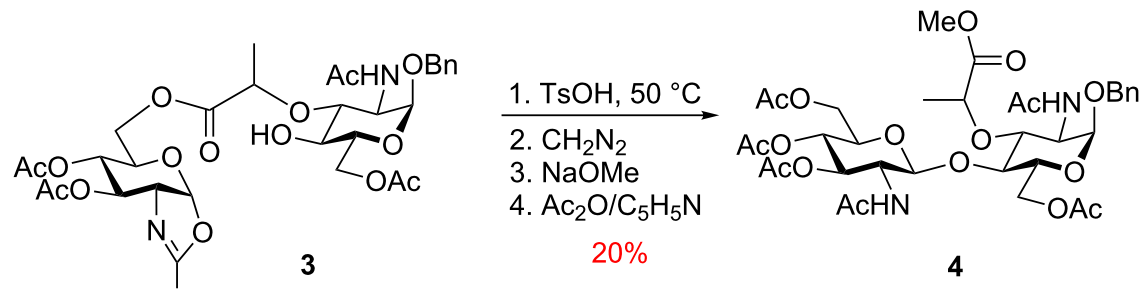
"entropic activation" in glycosidation reaction." The authors have also projected that the "entropic activation demonstrated in this work seems to have wide applicability..." and disclosed their attempts to link the reaction counterparts with dicarboxylic acids. This served as an ultimate perspective on future developments in the field, but about a decade had passed before Ziegler resurrected this concept.

\section{Flexible succinoyl and related tethers}

Ziegler and co-workers investigated the use of a flexible succinoyl linker to link the glycosyl donor and acceptor counterpart. This reaction was named "intramolecular glycosylation of prearranged glycosides" $[52,53]$. Like in all "molecular clamp" applications, the tethering of the reaction counterparts takes place at positions not directly involving glycosylation sites: acceptor hydroxy group, like in the IAD or the donor leaving group, like in the leaving group-based approaches. In accordance with Ziegler's execution of this concept shown in Scheme 3, glycosyl donor 5 equipped with the succinoyl group at $\mathrm{C}-2$ was coupled to the diol galactosyl acceptor 6 in the presence of DCC and DMAP. The resulting tether compound 7 was obtained in $63 \%$ yield. The intramolecular glycosylation of the latter gave cyclic compound $\mathbf{8}$ in $76 \%$ yield, which was sequentially deacylated and per-benzoylated to afford disaccharide 9 in $74 \%$ as a pure 1,2-trans isomer [52]. Expansion of this approach to other positions and sugar series showed that the stereoselectivity could be relaxed, and seemed to be dependent of the donor-acceptor match-mismatch. Thus, when succinoyl was attached to the 6-OH of the galactosyl acceptor, equal amounts of $\alpha$ - and $\beta$-anomers were obtained. Also, when a glucosyl acceptor was employed, mainly the 1,2-cis-linked product was obtained.

Valverde et al. also investigated succinoyl tethers [54], but their studies were mainly focusing on phthaloyl and non-symmetri- cal linkers described below. Among other flexible linkers investigated are carbonate [57], as well as oxalic [57], malonic [53,57,58], and glutaric [59] dicarboxylic acids. However, like in the case of succinoyl linkers, higher flexibility led to more relaxed stereoselectivity. Further variations upon this method involved the modification of the macrocycle ring size, torsional rigidity of the spacer, position of the attachment to both donor and acceptor, relative configuration of hydroxy groups, and the length of the linker [58,60-72]. Among early examples, xylylene and phthalimido linker showed very high efficiency, and will be highlighted below. Another early development discussed below is the peptide-templated synthesis. Beyond these influential early studies that led to further developments, this topic was comprehensively overviewed and for early developments the reader should refer to the original references and excellent comprehensive overviews of the topic [38,40]. It is a commonly accepted fact that the outcome of many glycosylations that fall under the general molecular clamp concept can be unpredictable. Therefore, practically every approach developed under this category was extensively studied and applied to a variety of sugar series and targets $[58,73,74]$.

\section{Phthaloyl and related tethers}

Phthaloyl tethering was also introduced by Ziegler [53] and practically concomitantly by Valverde et al. [54] as "templatedirected cyclo-glycosylation." In the latter application, glycosyl donor precursors were reacted with phthalic anhydride to afford the corresponding esters. The activation with thionyl chloride was used for tethering the donors to the glycosyl acceptor counterpart and the regioselectivity was controlled using tin-mediated coupling under microwave irradiation. The tethered compound 10 was then glycosylated in the presence of NIS/TfOH to afford compound 11 (Scheme 4). The tether was removed with $\mathrm{NaOMe}$ and the product was globally acetylated to afford $\mathbf{1 2}$ as an $\alpha-(1 \rightarrow 3)$-linked isomer. The regioselectivity in this case was

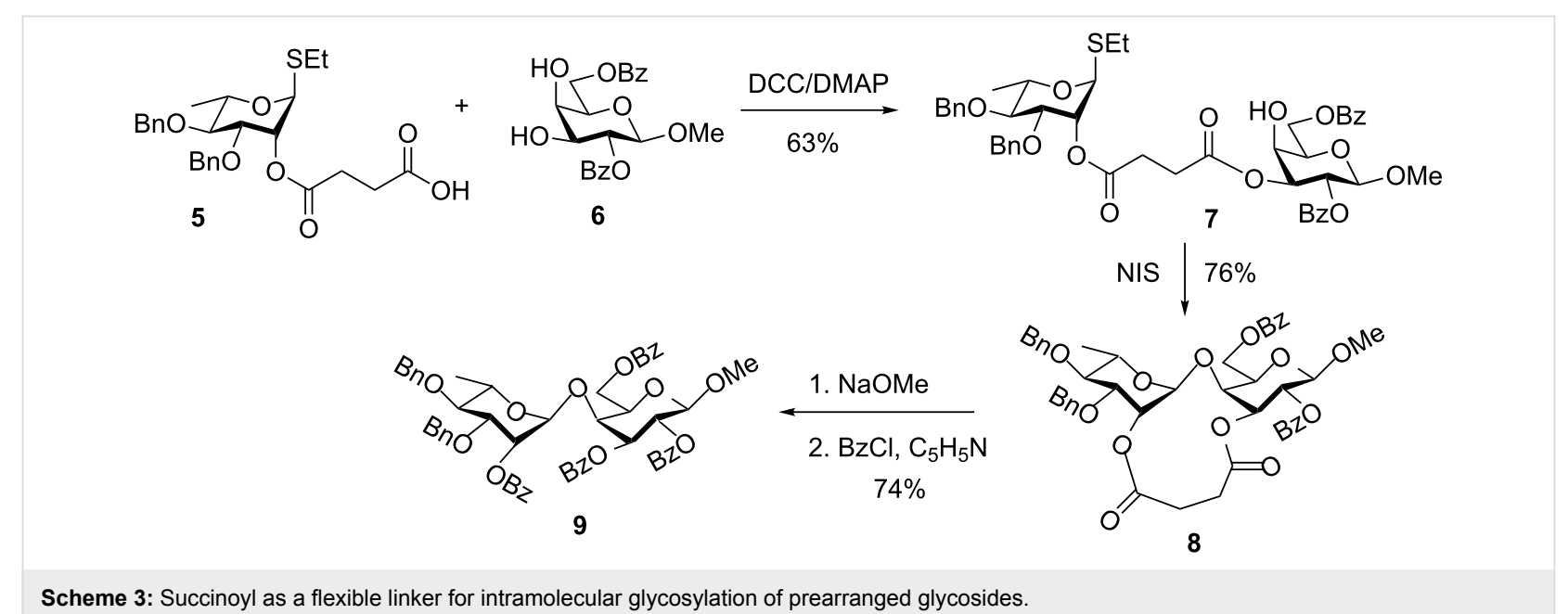

Scheme 3: Succinoyl as a flexible linker for intramolecular glycosylation of prearranged glycosides. 


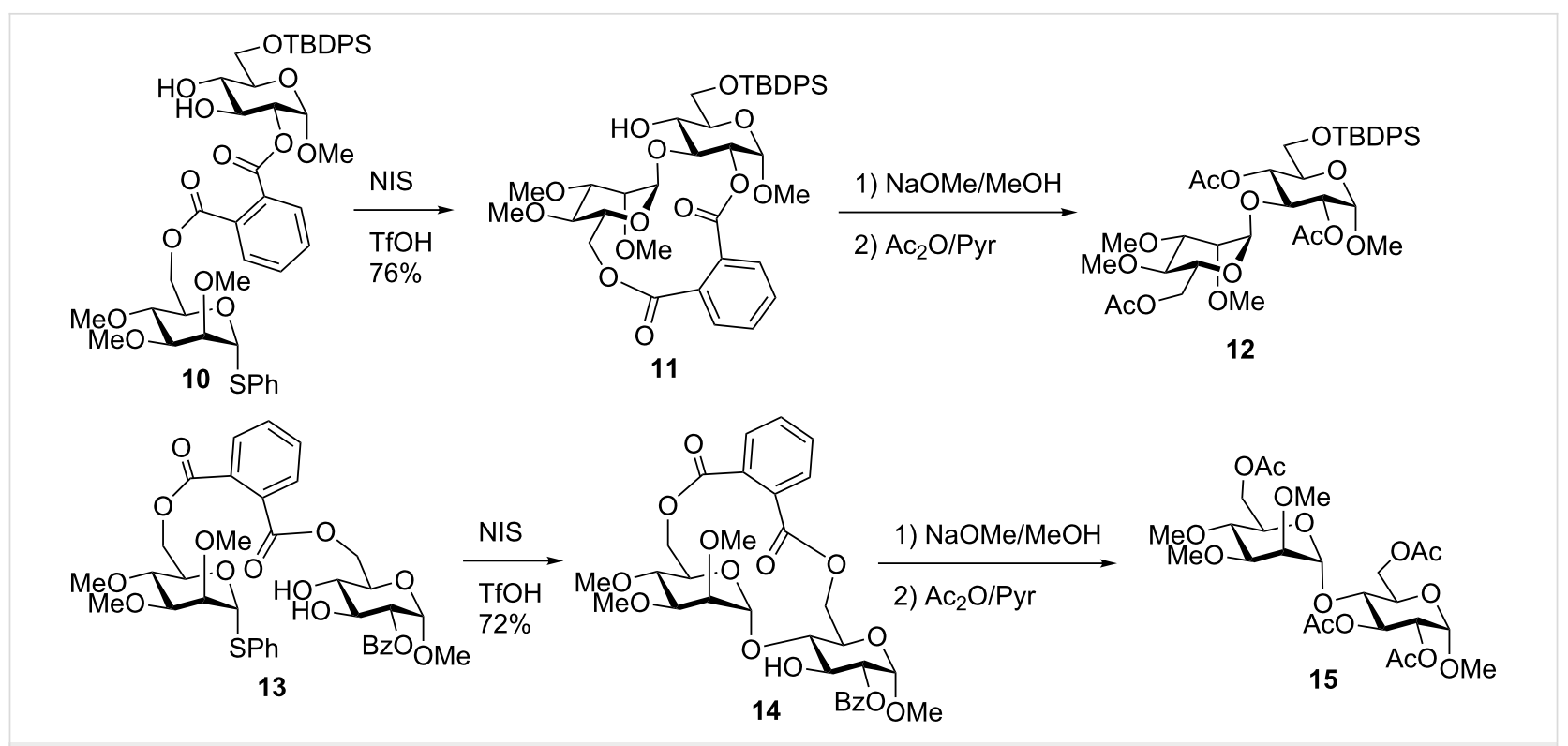

Scheme 4: Template-directed cyclo-glycosylation using a phthaloyl linker.

driven by the phthaloyl tether attachment to the neighboring C-2 position. In contrast, 6,6'-linked donor-acceptor pair 13 led to the formation of the $(1 \rightarrow 4)$-linked regioisomer 15 [64]. Apparently, the rigid phthaloyl tether helps to achieve high regioselectivity because the anomeric center of the activated donor cannot easily reach out for hydroxy groups at remote positions.

In other applications, such as in the glucosyl donor series, this application was less effective. For instance, relaxed regioselectivity was observed in cases when the phthaloyl linker was attached to the primary position of the acceptor [64]. Also, relaxed stereoselectivity was observed in case of glucosyl donors equipped with a non-participating group at C-2. Valverde at al. also investigated isophthalic tether, derived from benzene-1,3-dicarboxylic acid, and observed improved stereoselectivity in a number of applications [65]. The phthalimido tethering was further extended to a number of useful applications including the synthesis of branched structures by Takahashi and cyclodextrins by Fukase discussed below.

Thus, Takahashi et al. considered both flexible succinoyl and the rigid phthaloyl tether, but based on the outcome of the computational studies of relative conformations and energies chose the latter linker [55]. To apply the remote glycosidation methodology to the synthesis of the 4,6-branched trisaccharide, phthaloylated thioglycoside 17 was coupled with the 6-hydroxy group of the acceptor precursor $\mathbf{1 6}$ in the presence of DCC and DMAP (Scheme 5). The tethering was accomplished in 97\% yield and the resulting conjugate was converted into glycosyl fluoride by the treatment with DAST and NBS in
$89 \%$ yield. Finally, selective cleavage of $p$-methylbenzyl ethers was accomplished with $\mathrm{H}_{2}$ over $\mathrm{Pd}(\mathrm{OH})_{2} / \mathrm{C}$ to provide donor-accepter conjugate 18 in $93 \%$ yield. Subsequent remote glycosidation of $\mathbf{1 8}$ was conducted in the presence of $\mathrm{Cp}_{2} \mathrm{HfCl}_{2}$ and AgOTf in $\mathrm{CH}_{2} \mathrm{Cl}_{2}$ under reflux. The cyclized product 19 was obtained in $37 \%$ yield, the tether was removed with $\mathrm{NaOMe}$, and the resulting free hydroxy groups were acetylated to afford the branched trisaccharide $\mathbf{2 0}$.

The chemical synthesis of cyclodextrins is very challenging: controlling $\alpha$-gluco stereoselectivity, and especially the final cyclization, represent a great challenge. For example, in Ogawa's synthesis of $\alpha$-cyclodextrin the chain assembly was non-stereoselective and the cyclization was achieved in only $21 \%$ yield [75]. Kusumoto et al. clearly demonstrated the advantage of the molecular clamping in application to the synthesis of $\alpha$-cyclodextrin (Scheme 6) [51]. The tethering was used to improve the selectivity during the stepwise chain elongation via the coupling of maltose building blocks 21 and 22, as well as the efficiency of macrocyclization. The macrolactonization using the phthaloyl group clamp was accomplished using DCC and DMAP in refluxing 1,2-dichloroethane. A fairly high dilution $(0.04 \mathrm{M})$ allowed to achieve the formation of the cyclic ester in $79 \%$ yield. This impressive yield was explained by the ability of the phthaloyl clamping groups to present the oligosaccharide chain in a favorable conformation for cyclization. After hydrolyzing the anomeric protecting group, several conditions were tried to close the ring and glycosylation with the trichloroacetimidoyl leaving group in $\mathbf{2 3}$ activated with trimethylsilyl triflate gave the desired $\alpha$-linked product $\mathbf{2 4}$ in $66 \%$ yield [51]. 

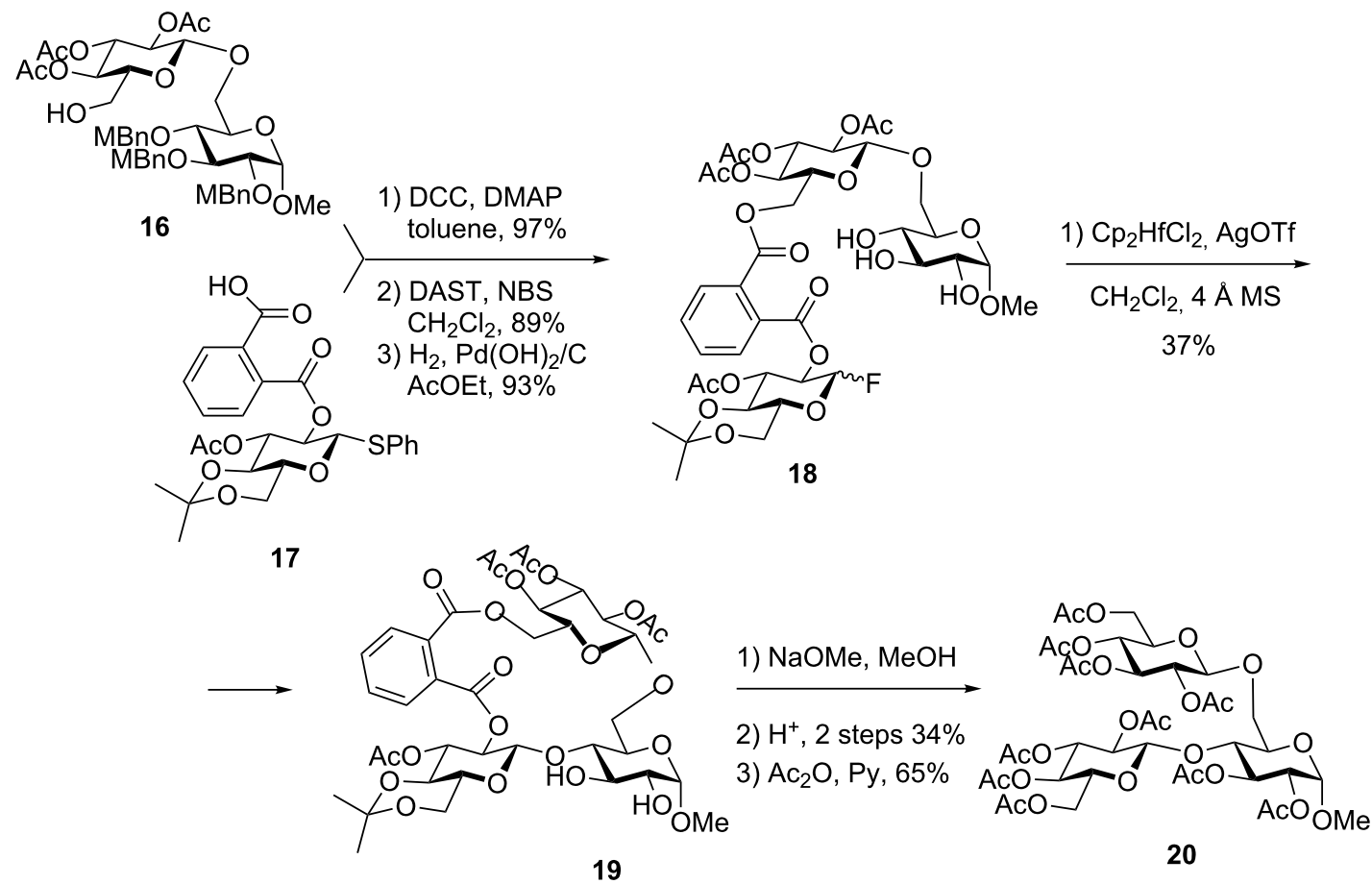

Scheme 5: Phthaloyl linker-mediated synthesis of branched oligosaccharides via remote glycosidation.

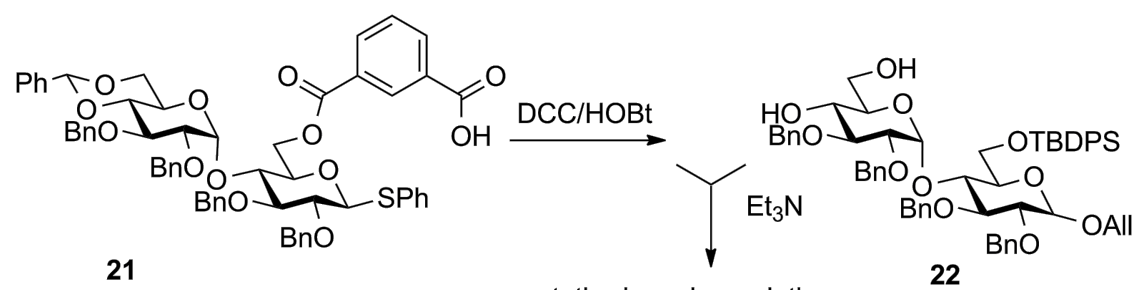

tethering, glycosylation,

22

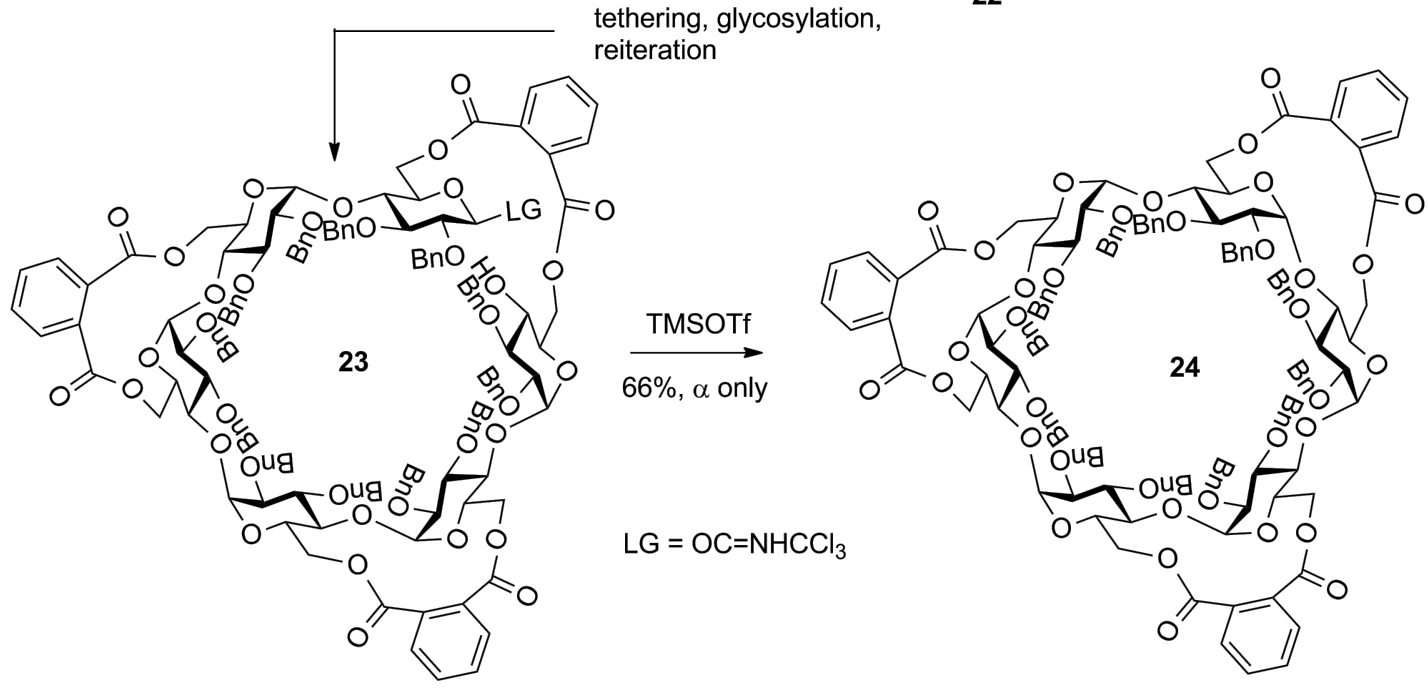

Scheme 6: Molecular clamping with the phthaloyl linker in the synthesis of $\alpha$-cyclodextrin. 


\section{Xylylene tether}

Generally during glycosylation, it has been found that the more rigid the spacers, and smaller macrocycle formed, the more selective the reaction $[63,69]$. As an example of this approach, a rigid xylylene linker introduced by Schmidt [68], was successfully applied to the intramolecular synthesis of 1,2-cis glycosides with complete selectivity (Scheme 7) [69]. Thus, thioglycoside $\mathbf{2 5}$ is first alkylated at C-3 position. The resulting intermediate $\mathbf{2 6}$ is then used as the alkylating reagent to create a tether to acceptor $\mathbf{2 7}$ using tin-mediated primary alkylation to afford the tethered pair $\mathbf{2 8}$.

The latter is then intramolecularly glycosylated in the presence of NIS/TfOH in $93 \%$ yield and complete stereoselectivity. The resulting cyclic compound $\mathbf{2 9}$ is then subjected to concomitant xylylene tether removal and debenzylation followed by global acetylation to afford product $\mathbf{3 0}$.

The extension of this approach to convergent oligosaccharide synthesis and reiterative sequencing in presented in Scheme 8. Thus, maltose and lactose disaccharide building blocks were linked via the xylylene tether, and the resulting compound $\mathbf{3 1}$ was glycosylated in the presence of NIS/TfOH to afford tetrasaccharide 32 in $78 \%$ as a pure $\beta$-diastereomer [70]. Schmidt demonstrated the usefulness of xylylene tethers in application to the iterative synthesis of maltotriose [70]. In this application, the xylylene tether was used to link two glucose derivatives via the 3'- and the 6-positions to create a tethered combination $\mathbf{3 3}$ (Scheme 8). NIS/TfOH was then applied to glycosylate the two sugar units to give disaccharide 34 in $84 \%$ yield $(\alpha / \beta=85: 15)$. Subsequent selective deprotection of the 6'-position, introduction of the new donor moiety $\mathbf{3 5}$ followed by liberating the hydroxy group at C-4' gave the tethered donor-acceptor combination 36. After the NIS/TfOH-promoted glycosylation the desired trisaccharide 37 was obtained in $75 \%$ yield as a pure $\alpha$-linked diastereomer. The per-acetylated maltotriose target was obtained after palladium-catalyzed hydrogenation that affected the removal of the template and all benzyl protecting groups followed by acetylation of the resulting hydroxy groups.

\section{Peptide tether/template}

Short peptide chains have also been investigated as templates for glycosylation. The general underpinning idea is to streamline the oligosaccharide synthesis and purification by using well developed peptide coupling reactions with or without the use of solid phase methods. To execute this concept, Fairbanks et al. investigated a number of peptide chains with various amino acids as templates (Scheme 9) [76,77]. Using DCC-mediated coupling reactions asparagine was attached both to a mannose donor and a trihydroxymannose acceptor, and the central amino acid unit(s) was varied. Intramolecular glycosylation was carried out with NIS/TfOH, resulting in a mixture of disaccharide products showing slight regioselectivity bias towards the formation of $(1 \rightarrow 3)$ linkages.

The stereoselectivity of these linkages can vary, but it was typically very relaxed perhaps due to a fairly low rigidity of this type of a template. Hence, further development of this methodology focused on solid-supported peptide templates [78]. For instance, Warriner and co-workers investigated a solid supported peptide sequence that was connected to the 6-hydroxy groups of the sugar units using carbonate linkages (Scheme 10) [79]. The hydroxyproline (Hyp, $(2 S, 4 R)$-4-hydroxypyrrolidine2-carboxylic acid) linked glycosyl donor and acceptor system failed to provide the product of the intramolecular glycosylation, probably due to steric interactions. A glycine residue spacer was found necessary to separate the two rigid Hyp bound counterparts. Thus, glycosylation of conjugate $\mathbf{3 8}$ in the presence of NIS and TMSOTf resulted in the formation of the $(1 \rightarrow 4)$-linked disaccharide $\mathbf{4 0}$ in $80 \%$ yield with high $\alpha$-selec-

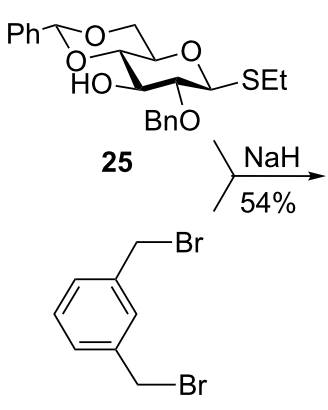

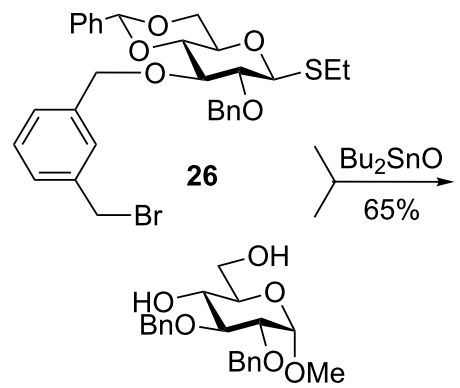

27

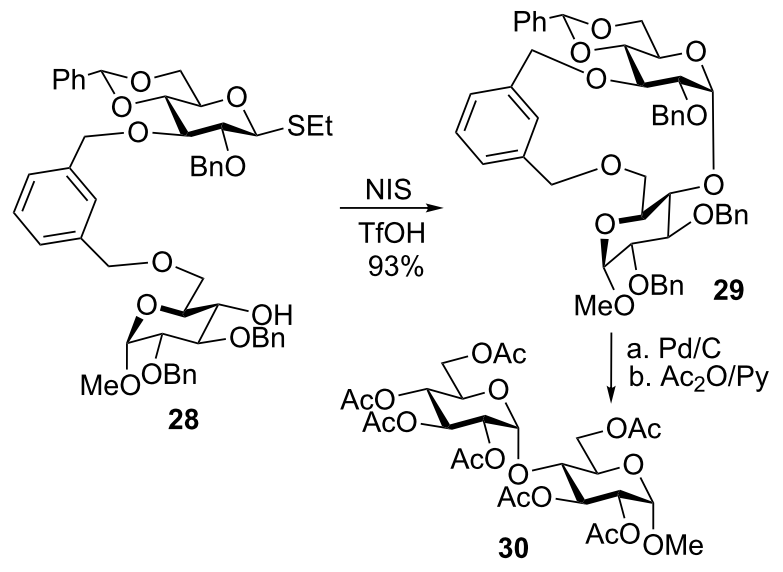




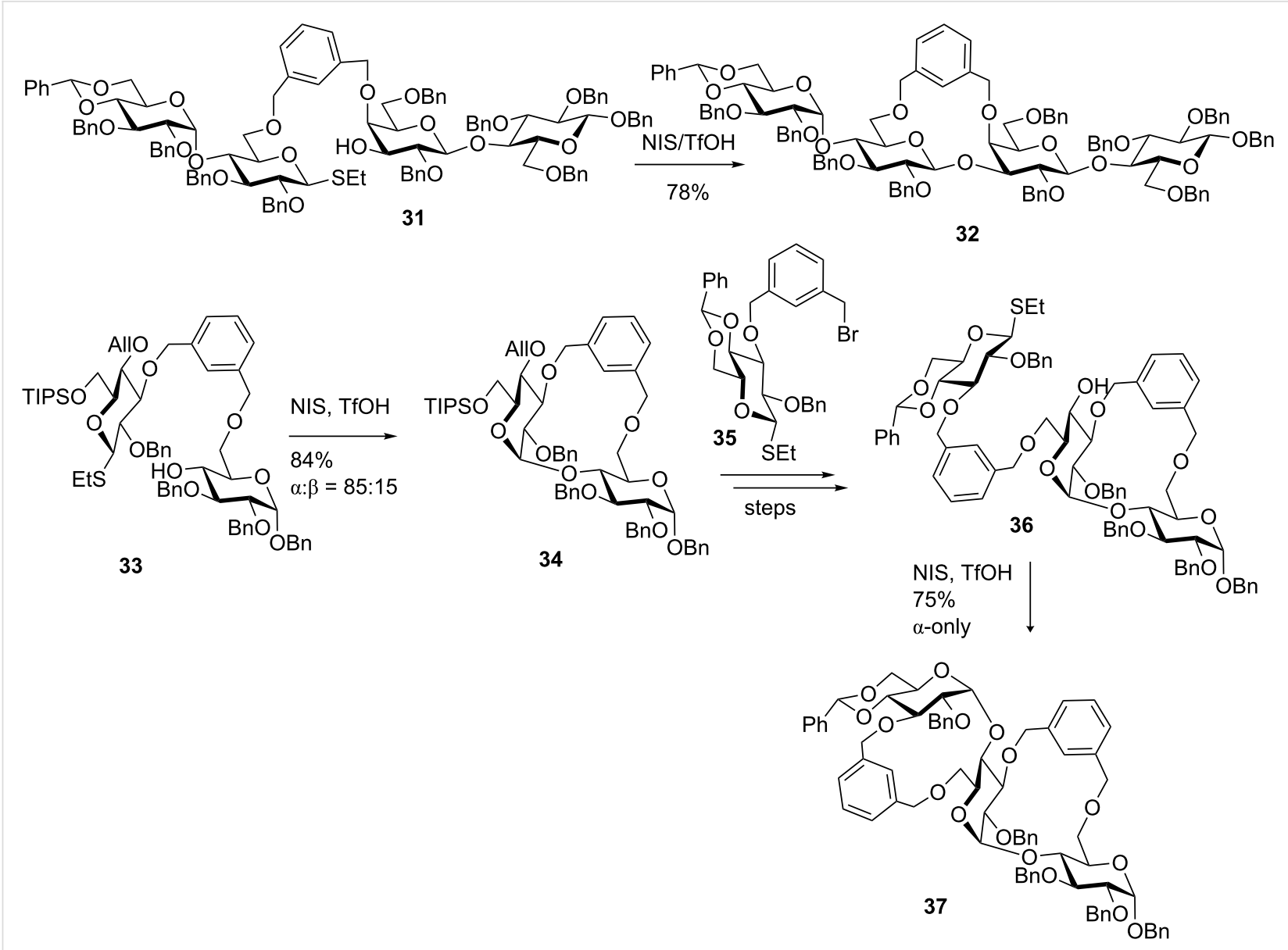

Scheme 8: Oligosaccharide synthesis using rigid xylylene linkers.

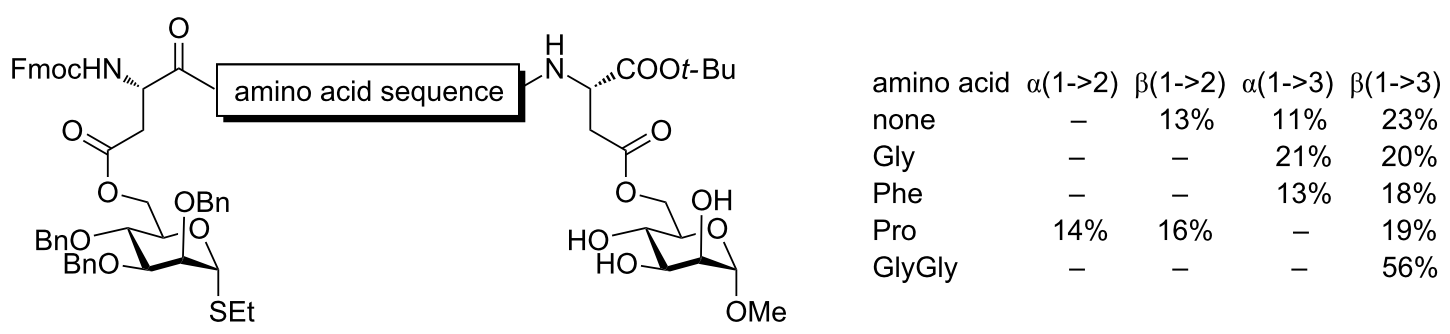

Scheme 9: Stereo- and regiochemical outcome of peptide-based linkers.

tivity $(\alpha / \beta=8: 1)$. Interestingly, when the donor and acceptor positions on the peptide were reversed, such as conjugate $\mathbf{3 9}$, glycosidation of this compound produced disaccharide 40 in $75 \%$ yield albeit the stereoselectivity was entirely lost $(\alpha / \beta=1: 1)$. Galactosyl acceptors also showed a dramatic effect of the relative position of the donor and acceptor on the peptide sequence. Intriguingly, the stereoselectivity outcome was reversed (1.8:1 and 9:1) in comparison to glucosyl acceptors. When a similar concept was applied to mannosyl acceptor low 2:1 stereoselectivity was obtained regardless of the relative positioning of the reaction counterparts. This peptide-based templating was extended to the synthesis of a small library of disaccharides.

\section{Non-symmetrical and other tethers}

Non-symmetrical templates have also been developed with a general idea of achieving differentially cleavable attachments that could provide more flexibility in the synthesis of longer oligosaccharides $[62,65]$. Some representative examples of this general concept include benzyl-silicon tether [72], which is a 


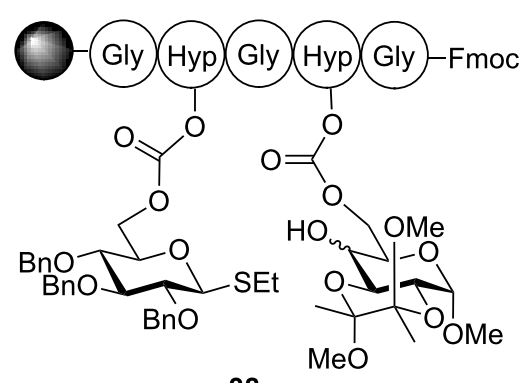

38

Glc: $80 \%, \alpha / \beta=8: 1$

Gal: $79 \%, \alpha / \beta=1.8: 1$

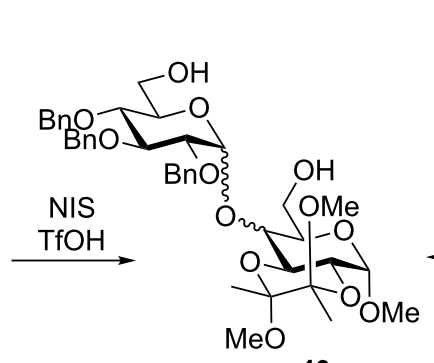

40

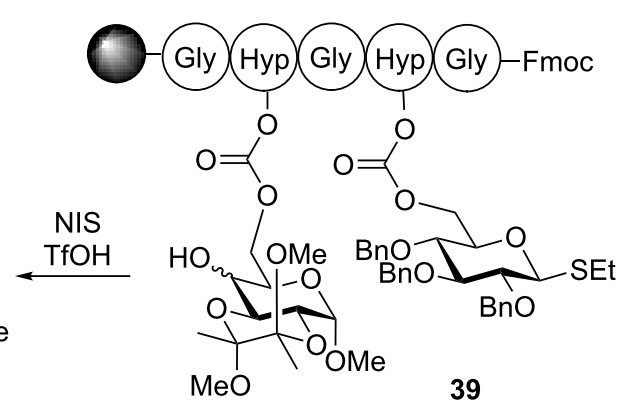

Glc: $75 \%, \alpha / \beta=1: 1$

Gal: $81 \%, \alpha / \beta=9: 1$

Scheme 10: Positioning effect of donor and acceptor in peptide templated synthesis.

hybrid approach to xylylene and a regular silicon [59] type of tethering. Another example of a non-symmetrical tethering strategy is benzyl-benzoyl hybrid tethering [72] that elaborated on xylylene and phthaloyl tethering approaches discussed above. Thus, this strategy was used in the synthesis of a trisaccharide through reiterative template-assisted synthesis (Scheme 11). Compound 41, wherein the donor and acceptor counterparts were subjected to tethering via this rigid hybrid linker, was subjected to the NIS/TfOH-promoted glycosylation. The tether in the resulting disaccharide $\mathbf{4 2}$ could then be selectively opened with $\mathrm{NaOMe}$. This leads to liberating only one hydroxy group (at C-3") that could be used for tethering with a glycosyl donor using a similar tethering concept to afford compound 43.
The second glycosylation reaction is conducted in the presence of iodine in methanol. These conditions allow to cleave benzylidene groups concomitantly with the activation of the leaving group. As a result, the formation of the 14-membered ring is observed and compound $\mathbf{4 4}$ obtained in $83 \%$ yield with complete $\alpha$-stereoselectivity. The ester part of the template is then cleaved with sodium methoxide in methanol revealing the 6"-hydroxy group that can be used for subsequent transformations [72].

In a recent attempt to simplify the synthesis of the non-symmetrical tethers, a highly trendy triazole-forming click chemistry was combined with rigid spacers by the Schmidt group. $\alpha, \alpha^{\prime}$-Dibromo ortho- and meta-xylene-derived rigid spacers were used in this application, and this approach allowed to in-

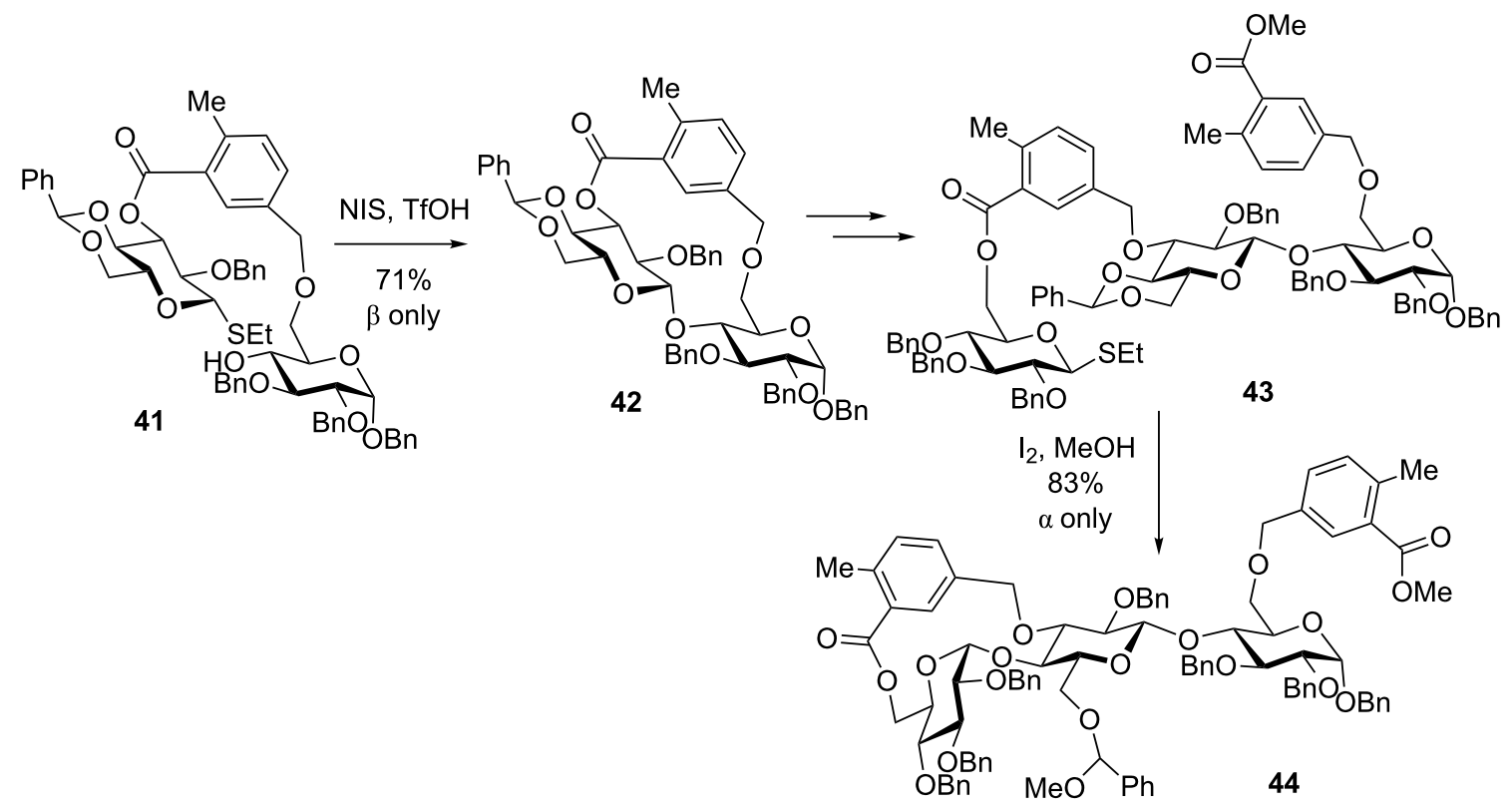


vestigate the size of the macrocycle formed during the glycosylation (Scheme 12) [80,81]. Thioglycoside donor $\mathbf{4 5}$ containing a 2-O-propargyl group and acceptor 46 with an azide-containing protecting group were connected using a click reaction to afford the tethered intermediate 47. Upon treatment with NIS/TfOH, disaccharide 48 was obtained with complete $\beta$-selectivity when the ortho-xylyl group (15-membered ring) was used, versus $\alpha / \beta=1: 3$ selectivity in the case of the meta-xylene linked counterpart [80]. As in the previous example with the xylylenederived linker, the triazole linker was removed under standard hydrogenation conditions followed by global acetylation. The results obtained with the 6-hydroxyglucopyranosyl acceptor were somewhat mixed [81]. Attaching the template at various positions of the acceptor to achieve either 16- or 17-membered macrocycles resulted in high yields of $90 \%$ and $82 \%$, respectively. However, the stereoselectivity of the reactions was modest, $\alpha / \beta=3: 1$ and $1: 2$, respectively.

With the observation that selectivity can be influenced by the size of the macrocycle formed as a result of the intramolecular glycosylation, a tethered system linked via the O-3 position with the acceptor 49 was obtained (Scheme 12). Following the NIS/TMSOTf-promoted glycosylation, macrocycle $\mathbf{5 0}$ was formed in 55\% yield with exclusive $\alpha$-stereoselectivity. Interest- ingly, when a similar template was attached to the O-2 position followed by glycosylation with the 3-hydroxy group, the reaction proceeded with high $\beta$-selectivity. With the varying anomeric stereoselectivities and yields, it was hypothesized that the benzylic methylene group may be responsible for the increased rotational freedom between the triazoyl and benzyl moieties. Investigations with $o$-azidobenzyl protecting groups were used to reduce the degrees of freedom and also to form smaller ring sizes [81].

\section{Templated oligosaccharide synthesis}

Recently, Demchenko and co-workers introduced templated oligosaccharide synthesis, wherein bisphenol A (BPA) was used as the template and succinoyl, glutaryl or phthaloyl linkers were used to tether glycosyl donors and acceptors together [56,82]. The templated synthesis also falls into the general molecular clamping method. High stereoselectivity could be achieved with both flexible and rigid linkers (L1 and L2, Scheme 13). However, the use of the rigid BPA template core appears to be the key to ensure the high stereoselectivity because with flexible peptide core, no difference in stereoselectivity was detected. Thus, if linker L1 is shorter than L2, succinoyl vs glutaryl, respectively (or the same length, succinoyl) in compound 51, the glycosyl acceptor counterpart is delivered from the bottom face

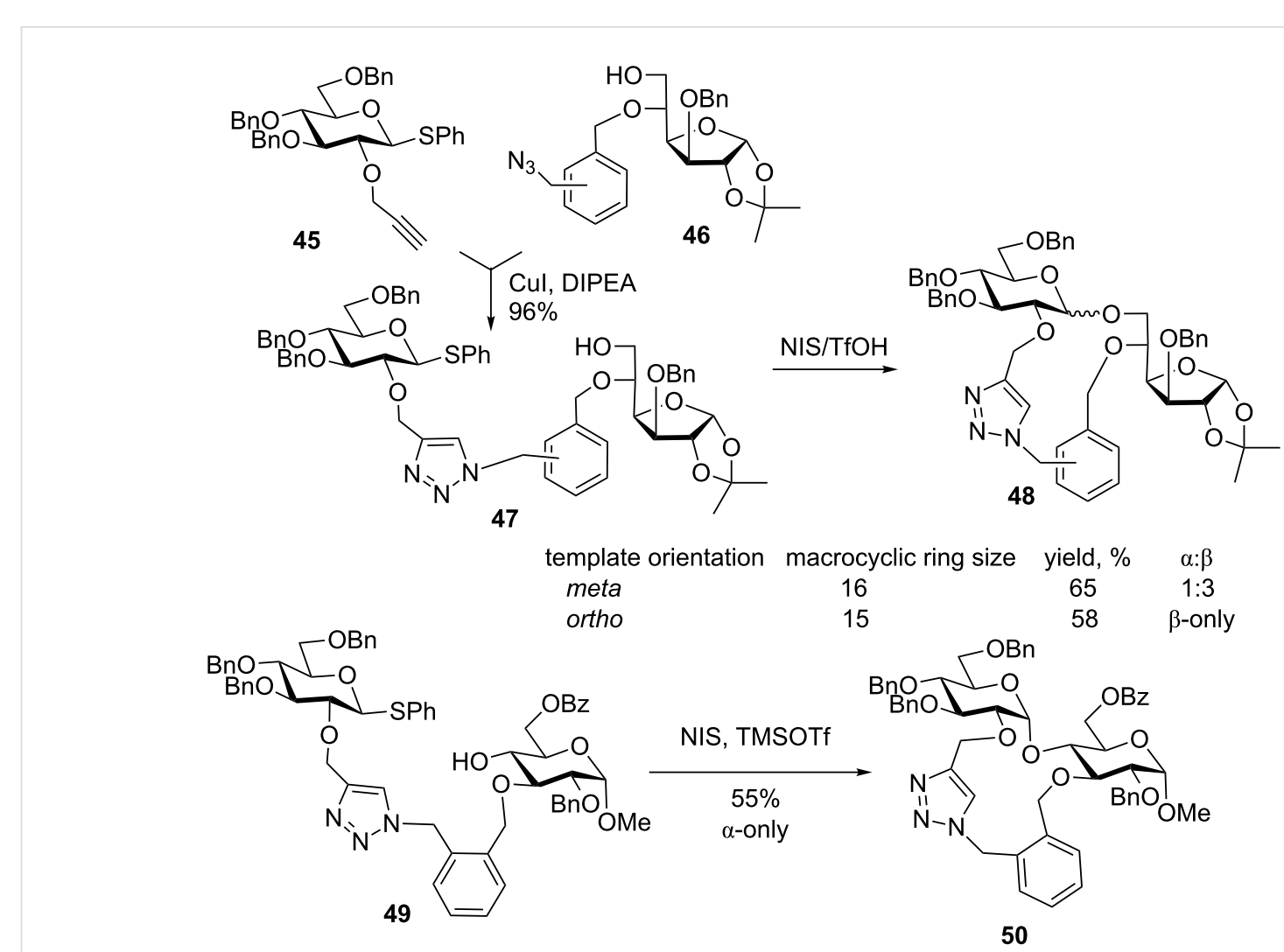

Scheme 12: Effect of ring on glycosylation with a furanose. 

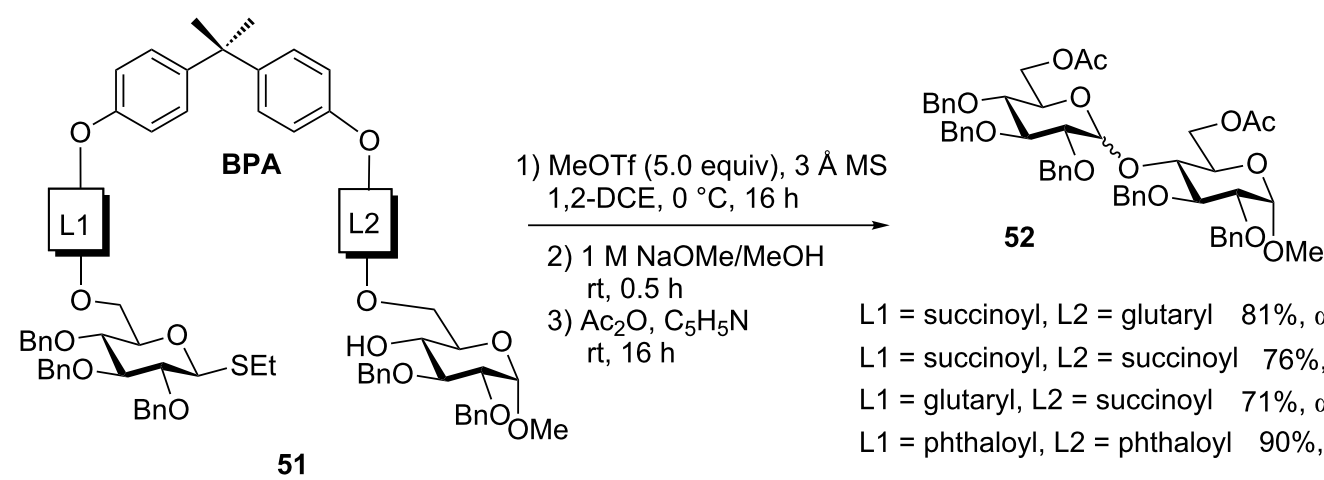

L1 = succinoyl, L2 = glutaryl $81 \%, \alpha$-only

L1 $=$ succinoyl, L2 = succinoyl $76 \%, \alpha$-only

$\mathrm{L} 1=$ glutaryl, $\mathrm{L} 2=$ succinoyl $71 \%, \alpha / \beta=2.8: 1$

L1 = phthaloyl, L2 = phthaloyl $90 \%, \alpha$-only

Scheme 13: Rigid BPA template with various linkers.

of the activated donor. These reactions produced the corresponding disaccharide 52 in $76-81 \%$ yields and complete $\alpha$-stereoselectivity. Conversely, if linker L1 is longer than L2, glutaryl vs succinoyl, respectively, the stereoselectivity is lost $(\alpha / \beta=2.8: 1)$. Interestingly, the template effect is stronger than that of a participating solvent acetonitrile that was unable to favor $\beta$-anomers, like in intramolecular glycosylations. Instead, complete $\beta$-selectivity could be achieved using glycosyl donors equipped with the participating group at $\mathrm{C}-2$.
A further mechanistic study of this work led to the appreciation of phthaloyl linkers leading to better yields, albeit complete $\alpha$-selectivity [82]. To demonstrate the utility of the method a trisaccharide was synthesized using trimellitic anhydride as a precursor for the bridging linker (Scheme 14) [56]. The more flexible succinoyl linkers showed a clear advantage over more rigid phthaloyl linkers in terms of stereoselectivity and yields. Thus, a tethered donor-central unit conjugate $\mathbf{5 3}$ was coupled with the BPA-conjugated glycosyl acceptor 54 using DCC/DMAP-medi-

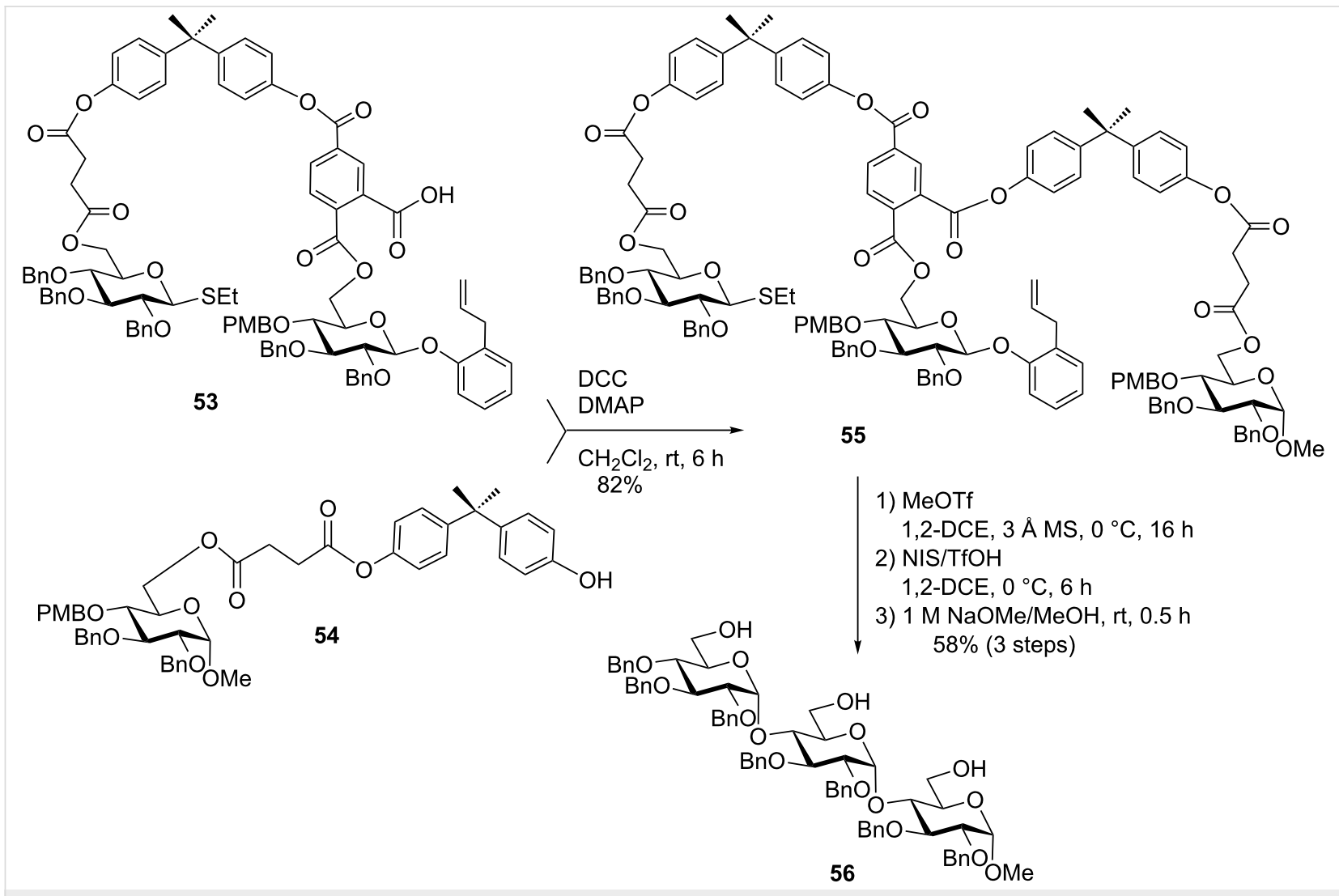

Scheme 14: The templated synthesis of maltotriose in complete stereoselectivity. 
ated coupling reaction to obtain the templated conjugate of three monosaccharide units $\mathbf{5 5}$ in $82 \%$ yield. The selective activation of the $S$-ethyl leaving group in compound $\mathbf{5 5}$ was achieved with MeOTf and the glycosylation of the central building block took place with concomitant removal of the $p$-methoxybenzyl (PMB) group. The $o$-allylphenyl leaving group was activated with NIS/TfOH, and again the PMB group of the acceptor was removed during the glycosylation step. The resulting maltotriose $\mathbf{5 6}$ was then released from the template by reaction with $\mathrm{NaOMe}$ in $\mathrm{MeOH}$ [56].

\section{Intramolecular aglycone delivery (IAD)}

This approach was invented by Barresi and Hindsgaul [45] who named it intramolecular aglycone delivery (aglycon in the original literature) and it is commonly abbreviated as IAD (approach B, Figure 1). The distinctive characteristic of the IAD methods, and its major difference from other intramolecular approaches is the glycosyl donor which is tethered directly via the hydroxy group of the glycosyl acceptor to be glycosylated. In all other approaches, the acceptor is linked away from the hydroxy group that is to be glycosylated. The tethering site at the glycosyl donor can be either the neighboring C-2 position or a remote position. Barresi and Hindsgaul employed the activation of the thioethyl leaving group with $\mathrm{N}$-iodosuccinimide, which resulted in excellent stereoselectivity for the synthesis of challenging $\beta$-mannoside $[45,83]$. Overall, this is a two-step process: first, formation of the intermolecular ketal between the donor and acceptor counterpart, and then glycosylation directly on the ketal oxygen of the glycosyl acceptor is performed. This was accomplished by the treatment of 2-isopropenylmannose 57 in the presence of $\mathrm{TsOH}$ (Scheme 15) to obtain mixed ketal $\mathbf{5 9}$. The second step involved glycosidation in the presence of NIS that produced disaccharide $\mathbf{6 0}$ in $42 \%$ yield and complete $\beta$-selectivity. Despite fair yields during both the ketal formation and glycosylation stage, this excellent idea gave rise to the development of procedures that helped to evolve the IAD method into a very effective methodology. In particular, the implementation of silyl, allyl, and more recently, naphthylmethyl tethers helped to achieve significantly higher yields in comparison to those reported in the original protocols. Since the IAD has been overviewed multiple times [41,48-50], presented herein are only the basics as well as the key recent developments of this.

Stork and Bols independently demonstrated that silicon bridgemediated aglycone delivery helps to enhance the yields while maintaining excellent stereocontrol $[84,85]$. For example, the Stork group used chlorodimethylsilyl protected acceptor precursor 62 for conjugation to the 2-hydroxy group of donor 61 as shown in Scheme 15. The thiophenyl leaving group of the tethered compound 63 was then oxidized into the corresponding sulfoxide with $m$-CPBA. The latter was glycosidated in the presence of $\mathrm{Tf}_{2} \mathrm{O}$ to afford disaccharide 64 in complete stereoselectivity and a good yield of $61 \%$ over two steps ( $73 \%$ from the sulfoxide intermediate). This dimethylsilyl linker strategy was also applied towards the synthesis of $\alpha$-glucosides by Bols [85].

Subsequently, the Bols group expanded the scope of the IAD method by investigating long-range tethering [39,85-89]. In this application the tether attachment was placed away from the
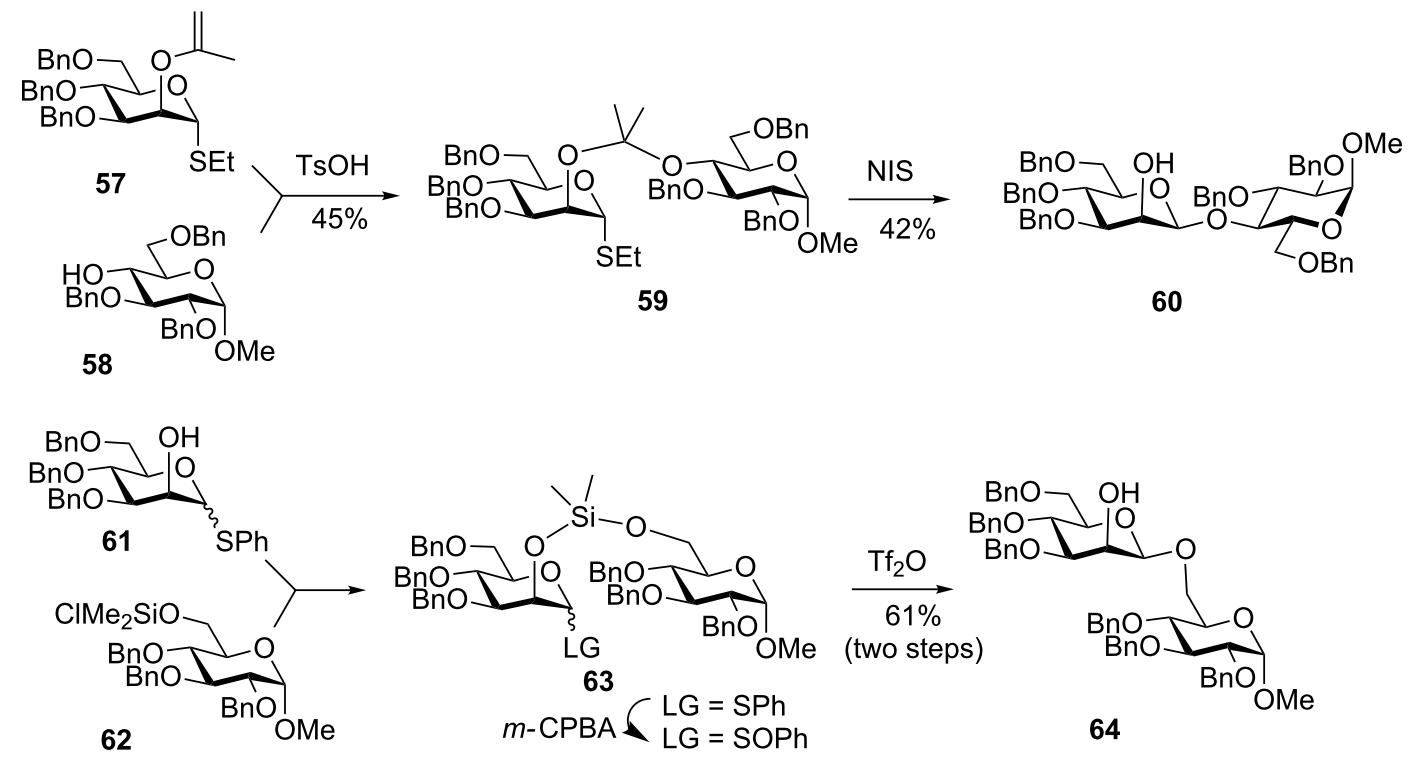
anomeric center offering a more flexible mode for obtaining either 1,2-cis or 1,2-trans linkages depending on the placement of the tether. While complete stereoselectivities were obtained with a ribofuranosyl donor tethered at C-5, application of the long range IAD towards glucopyranosides was less successful. Among a variety of attachment points, only tethering from the C-4 position showed some promise favoring the formation of the 1,4-syn products. Unfortunately, the IAD from the C-3 position afforded a mixture of diastereomeric glycosides, whereas tethering from the $\mathrm{C}-6$ position gave predominantly the 1,6-anhydro product.

Following upon the early studies by Stork and Bols, Montgomery et al. further expanded the idea of the long range IAD via silicon tethering [90]. In the most recent report, they hypothesized that the conformational restriction of the pyranose should position the C- 6 oxygen of the donor away from the developing oxacarbenium intermediate, thereby circumventing the formation of the cyclized product [91]. This was achieved by protecting the 3,4-trans-diol with a cyclic bis-ketal. Primary aliphatic alcohols underwent glycosylation very readily with donor 65 affording glycosides in excellent yields with high $\beta$-selectivity ( $>1: 32)$. With primary glycosyl acceptors, such as 66 (Scheme 16), yields were slightly diminished due to the formation of the homocoupling products. Secondary alcohol acceptors were even less efficient showing a high substrate specificity of this approach. Other donor series including 2-azido and 2-deoxy sugars were investigated and provided similar results. This method was also applied towards the delivery of acceptors from the neighboring C-2 position [91]. This approach tolerated a much wider range of acceptors and showed excellent stereoselectivity with secondary acceptors providing high yields and complete stereoselectivities: $\alpha$ - for glucosides and $\beta$ - for mannosides.
Another direction in the development of the IAD method emerged with the introduction of the allyl-mediated strategy by Fairbanks and co-workers who achieved improved yields and complete stereoselectivity in $\alpha$-glucosylations and $\beta$-mannosylations [92]. In accordance with the linking strategy, the vinyl ether $\mathbf{7 0}$ was obtained in $98 \%$ yield from the corresponding 2-O-allyl ether 69 by the treatment with Wilkinson's catalyst and BuLi (Scheme 17) [93]. Subsequent NIS-mediated tethering of $\mathbf{7 0}$ and acceptor $\mathbf{7 1}$ gave the tethered donor-acceptor pair 72. The latter was then intramolecularly glycosylated in the presence of silver triflate, tin(II) chloride, and 2,6-di-tert-butyl4-methylpyridine (DTBMP). Finally, the tether was cleaved off using TFA to give pure 1,2-cis glycoside $\mathbf{7 3}$ in $63 \%$ yield over two steps.

An alternative linker was developed by Ito and Ogawa who implemented DDQ-mediated oxidative transformation of the $p$-methoxybenzyl (PMB) protecting group at the $\mathrm{C}-2$ position of the donor into a tethering mixed acetal with a hydroxy group of the acceptor [94]. The early studies have successfully applied this PMB-based IAD method to the synthesis of a variety of oligosaccharides and glycoconjugates containing challenging $\beta$-mannosides $[95,96]$. A very impressive application of the IAD in polymer-supported reactions has also emerged [97]. Interestingly, the PMB tether was although used as the linker for the attachment to the polymer support. Bertozzi et al. investigated a similar concept based on 3,4-dimethoxybenzylidene tethering that was found superior in application to the synthesis of $\alpha, \alpha$-linked trehalose derivatives [98,99].

A major improvement of this approach has emerged with the implementation of a 2-napthylmethyl group as a tether group into this strategy [100]. This adjustment has allowed a greater range of hindered glycosyl acceptors to be tethered and glyco-
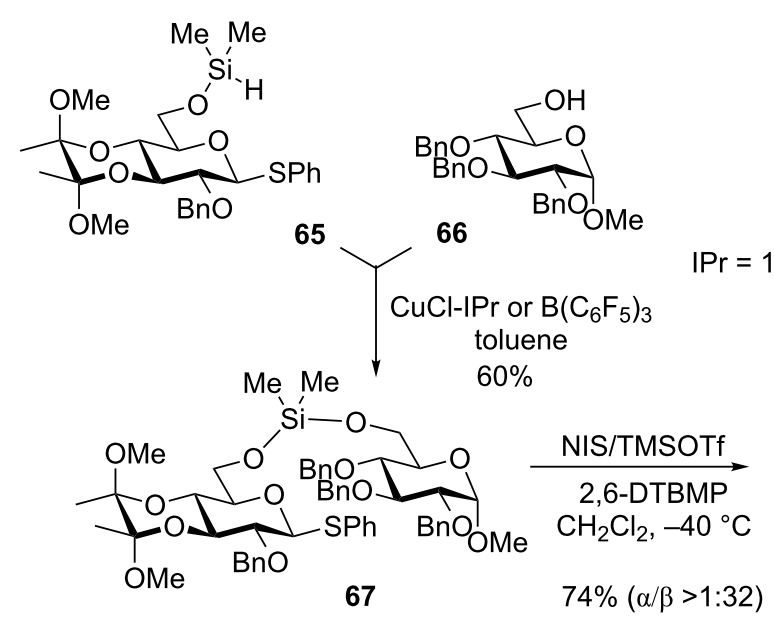

$\operatorname{Pr}=$ 1,3-bis(2,6-diisopropylphenyl)imidazol-2-ylidene

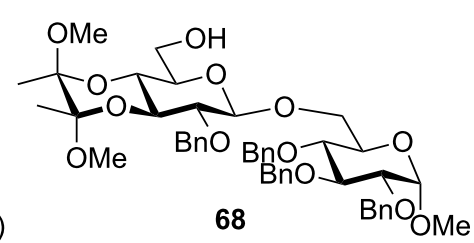

Scheme 16: Long range IAD via dimethylsilane. 


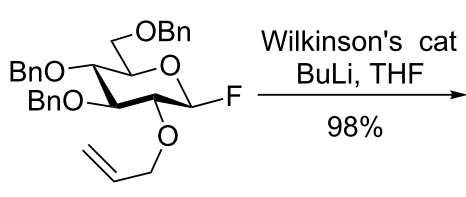

69
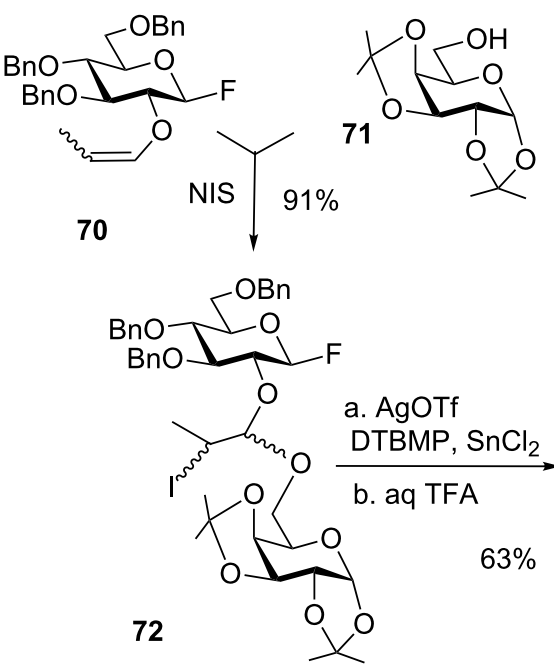

Scheme 17: Allyl-mediated tethering strategy in the IAD.

sylated in high yields and stereoselectivity. The versatility of this approach lies in that it generally provides significantly higher yields in comparison to practically all previously developed IAD approaches. A representative example depicted in Scheme 18 shows the synthesis of disaccharide 77, which clearly demonstrates that in terms of the over-all yields. This approach can even compete with direct intermolecular glycosylations while providing excellent stereoselectivity. Thus, mixed acetal 76 can be readily formed in $2 \mathrm{~h}$ by the addition of DDQ to a mixture of donor $\mathbf{7 4}$ and acceptor $\mathbf{7 5}$. Without further purification, the latter mixture can be glycosylated in the presence of MeOTf and DTBMP followed by acetylation to give disaccharide 77 in an excellent yield of $90 \%$ and complete $\beta$-selectivity [100]. Initially investigated for the synthesis of $\beta$-mannosides, $\alpha$-glucosides, and $\beta$-arabinofuranosides [100], this approach was extended to the synthesis of $\beta$-rhamnosides $[101]$ and many other challenging linkages and targets $[41,102-$ 108].

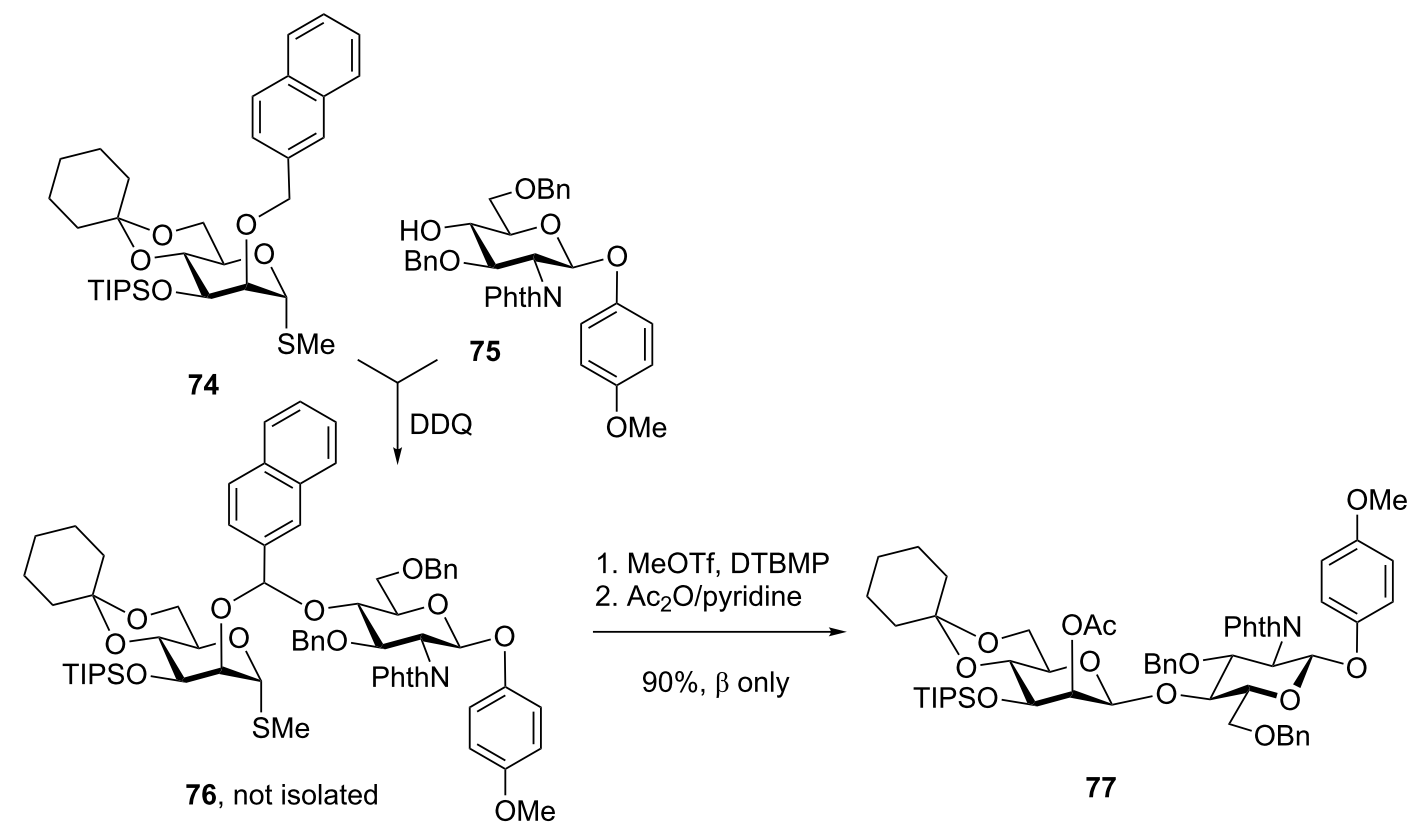

Scheme 18: IAD using tethering via the 2-naphthylmethyl group. 
Arylboronic esters have recently been probed by Toshima and co-workers as a successful linkage for the IAD method [109]. The arylboronic sugar derivatives, such as $\mathbf{7 9}$, can be easily obtained from the corresponding 4,6-diol $\mathbf{7 8}$ and a arylboronic acid in toluene at reflux (Scheme 19). Boronic ester $\mathbf{7 9}$ was then reacted with 1,2-anhydro donor $\mathbf{8 0}$. It was assumed that this reaction proceeds via the oxacarbenium ion tethered to a tetracoordinated boronate ester. The subsequent glycosylation then proceeds regioselectively from the less-hindered boron-oxygen bond (see intermediate $\mathbf{A}$ ). In this case, where gluco-configured acceptor $\mathbf{7 8}$ was used the $(1 \rightarrow 4)$-linked product $\mathbf{8 1}$ was formed exclusively in $82 \%$ yield with high $\alpha$-selectivity. Similarly, when mannose, glucosamine, and glucal were used as glycosyl acceptors, the $1 \rightarrow 4$ linkage was formed exclusively with high $\alpha$-selectivity in $92 \%, 77 \%$, and $72 \%$ yield, respectively. Conversely, the galacto-configured boronic ester acceptor $\mathbf{8 2}$ was used, the $\alpha$ - $(1 \rightarrow 6)$-linked product $\mathbf{8 3}$ was formed in $70 \%$ yield. Again, the regioselectivity of glycosylation is driven by the less-hindered boron-oxygen bond, which is from C-6 face in the case of galactose (intermediate $\mathbf{B}$, Scheme 19). In the case of other acceptors: a 3,4-diol of galactose gave the $\alpha-(1 \rightarrow 4)$ linkage predominantly $(65 \%)$ while a 2,3-diol of mannoside led to the $\alpha-(1 \rightarrow 3)$-linked disaccharide in $70 \%$ yield.

This method has recently found a valuable extension to the synthesis of $\beta$-mannosides [110]. Thus, diphenylborinic acid- derived glycosyl acceptors $\mathbf{8 4 - 8 6}$ were reacted with 1,2-anhydromannosyl donor $\mathbf{8 7}$ (Scheme 20). The tethered oxacarbenium ion intermediate then directs the nucleophilic attack intramolecularly to the $\beta$-face of the mannosyl donor. As a result, disaccharides 88-90 were obtained in $83-99 \%$ yields and exclusive $\beta$-manno stereoselectivity. Advantages of this methodology have been tested in application to the synthesis of a tetrasaccharide repeating unit of lipopolysaccharide derived from E. coli $\mathrm{O} 75$ [111].

Demchenko and co-workers introduced the use of the picolinyl group at the neighboring C-2 position of glycosyl donors as an arming participating group $[112,113]$. These glycosylations provided complete 1,2-trans stereoselectivity, anti with respect to the orientation of the picolinyl group. When the picolinyl ether or picoloyl ester group was placed at remote positions, glycosylations occurred syn with respect to the orientation of the picolinyl/picoloyl group [114]. The stereoselectivity was explained by the occurrence of the hydrogen bonding between the hydroxy group of glycosyl acceptor $(\mathrm{NuH})$ and the nitrogen atom of the picolinyl/picoloyl group. Subsequently, the glycosyl acceptor is delivered towards the oxacarbenium ion from the same face (syn) as the picolinyl/picoloyl group (Figure 2). This method, named H-bond-mediated aglycone delivery (HAD), has been applied towards the synthesis of $\alpha$-glucosides [114-116], $\alpha$-galactosides, $\beta$-rhamnosides [114], and $\beta$-mannosides [117].

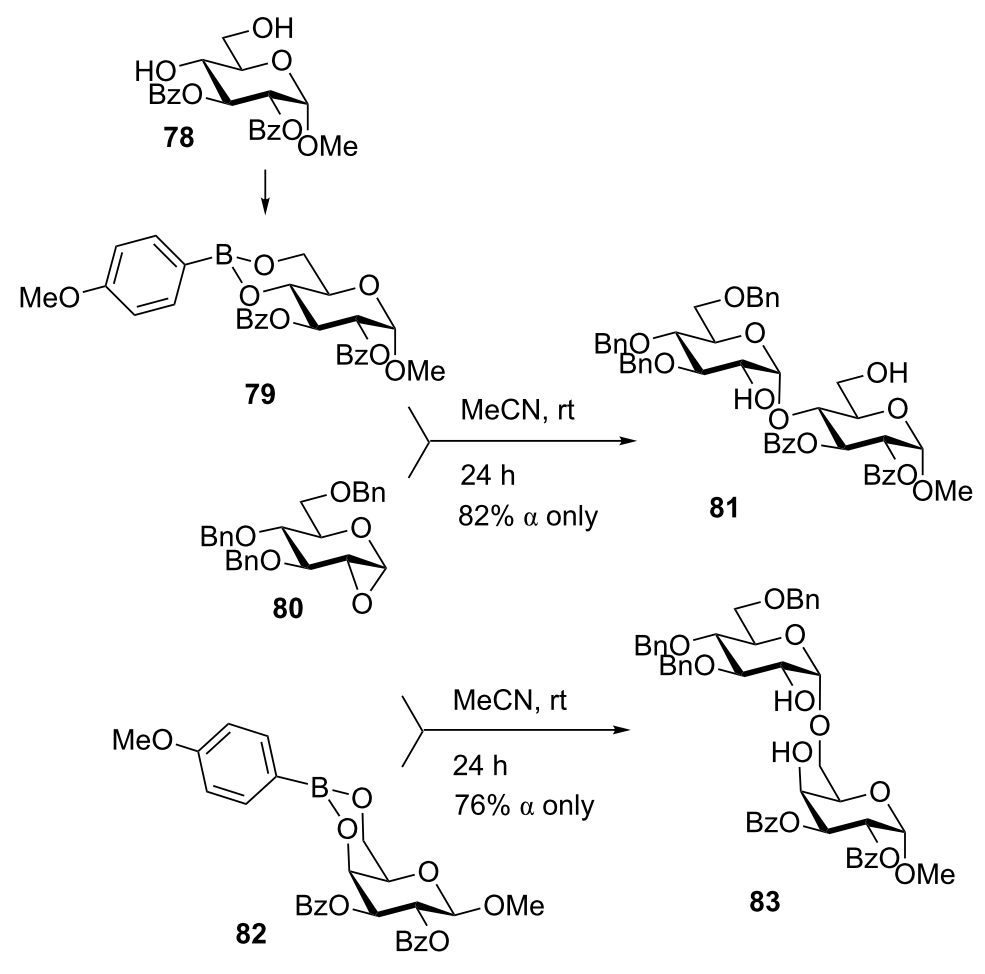

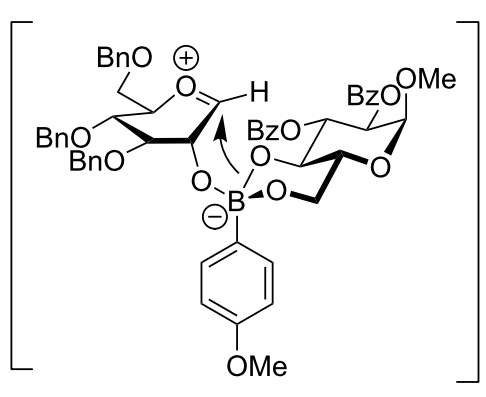

A: glyco-configured acceptor

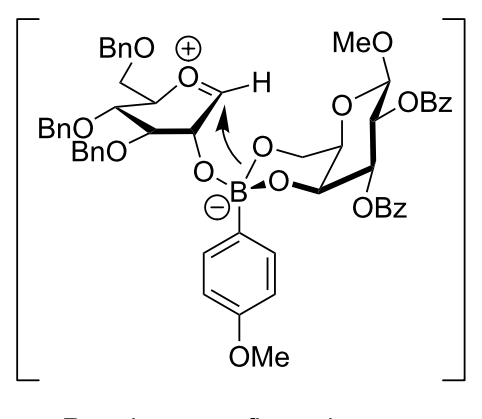

B: galacto-configured acceptor 


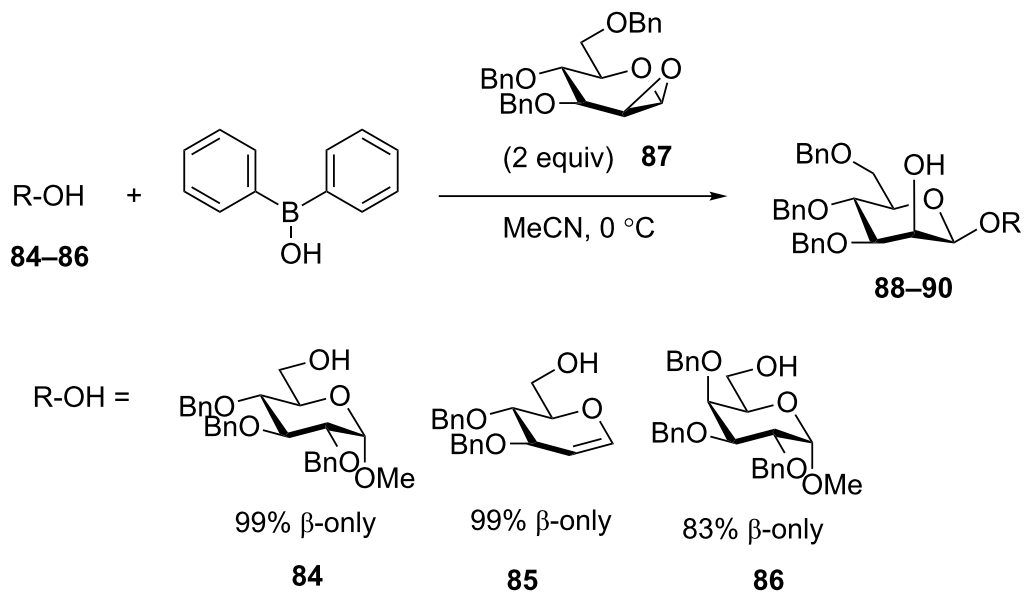

Scheme 20: Arylborinic acid approach to the synthesis of $\beta$-mannosides.

The latter approach was extended to the synthesis of a $\beta$-mannotrisaccharide, wherein complete $\beta$-manno selectivity was obtained at room temperature [117]. A useful extension of this method to glycosyl donors with switchable selectivity has also been disclosed by the Demchenko group [118,119].
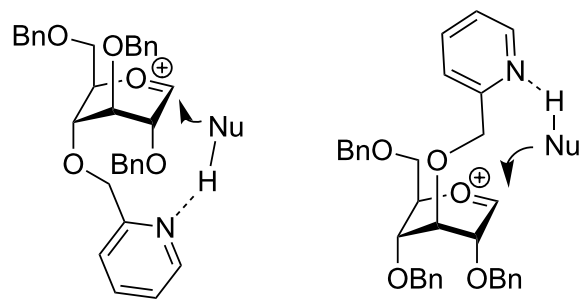

Figure 2: Facial selectivity during HAD.

Not being strictly intramolecular, the HAD method led to a variety of other delivery methods, which included the realm of organometallics. For instance, Liu and co-workers have developed the use of catalytic palladium to control the stereoselectivity in glycosylations via a palladium $\pi$-allyl intermediate. Previously, the application of this technique to glycosidic bond formation has been hampered by the difficulty in the formation of the palladium $\pi$-allyl intermediates and their poor reactivity in the electron-rich glycal systems [120]. To overcome this challenge the Liu group explored the application of palladium $\pi$-allyl intermediates to $O$-glycosylation through the use of a picoloyl group to direct palladium binding at the C-3 position [121]. Glycosylation results are indicative of two reaction pathways with differing in the selectivity outcome based on the hard/soft properties of the nucleophiles. In both pathways, the first step involves picoloyl group-directed coordination of palla- dium from the top $\beta$-face of the 1,2-dehydro donor 91 to form intermediate 92 (Scheme 21). With softer nucleophiles, such as phenol (ArOH), the nucleophilic attack is directed away from the steric bulk of the palladium to give $\alpha$-glycosides 93 . When the acceptor is a hard nucleophile, such as a sugar alcohol ( $\mathrm{SugOH}$ ), the picoloyl group is displaced to generate the $\pi$-allyl complex 94. The harder nucleophiles then tend to coordinate to palladium via intermediate $\mathbf{9 5}$, followed by intramolecular nucleophilic delivery to form $\beta$-anomer 96. Both primary and secondary sugar acceptors worked well providing disaccharides with high $\beta$-selectivity and good yields. Overall, compounds $\mathbf{9 3}$ and 96, obtained as a result of this interesting reaction, represent products of the Ferrier rearrangement, 2,3-dehydro derivatives.

\section{Leaving group-based methods}

This overview continues with the discussion of the leaving group-based tethering concept (approach C, Figure 1). As the name of the concept implies, the glycosyl acceptor is linked (away from the glycosylation site) to the leaving group of the glycosyl donor. The first examples of this type of intramolecular glycosylation was based on the 1,2-orthoester rearrangement by Lindberg [42] and Kochetkov [43], as well as the decarboxylation of glycosyl carbonates by Ishido [44]. Intramolecular glycosylations where the glycosyl acceptor was purposefully attached directly to the leaving group of the glycosyl donor have been introduced by the Schmidt group [122]. The applicability of these techniques is still relatively unexplored, yet, it has been proposed that these reactions tend to be intermolecular rather than intramolecular $[123,124]$. Subsequent studies involved the exploration of various reaction conditions $[125,126]$, and the investigation of other leaving groups $[123,124,127]$. 


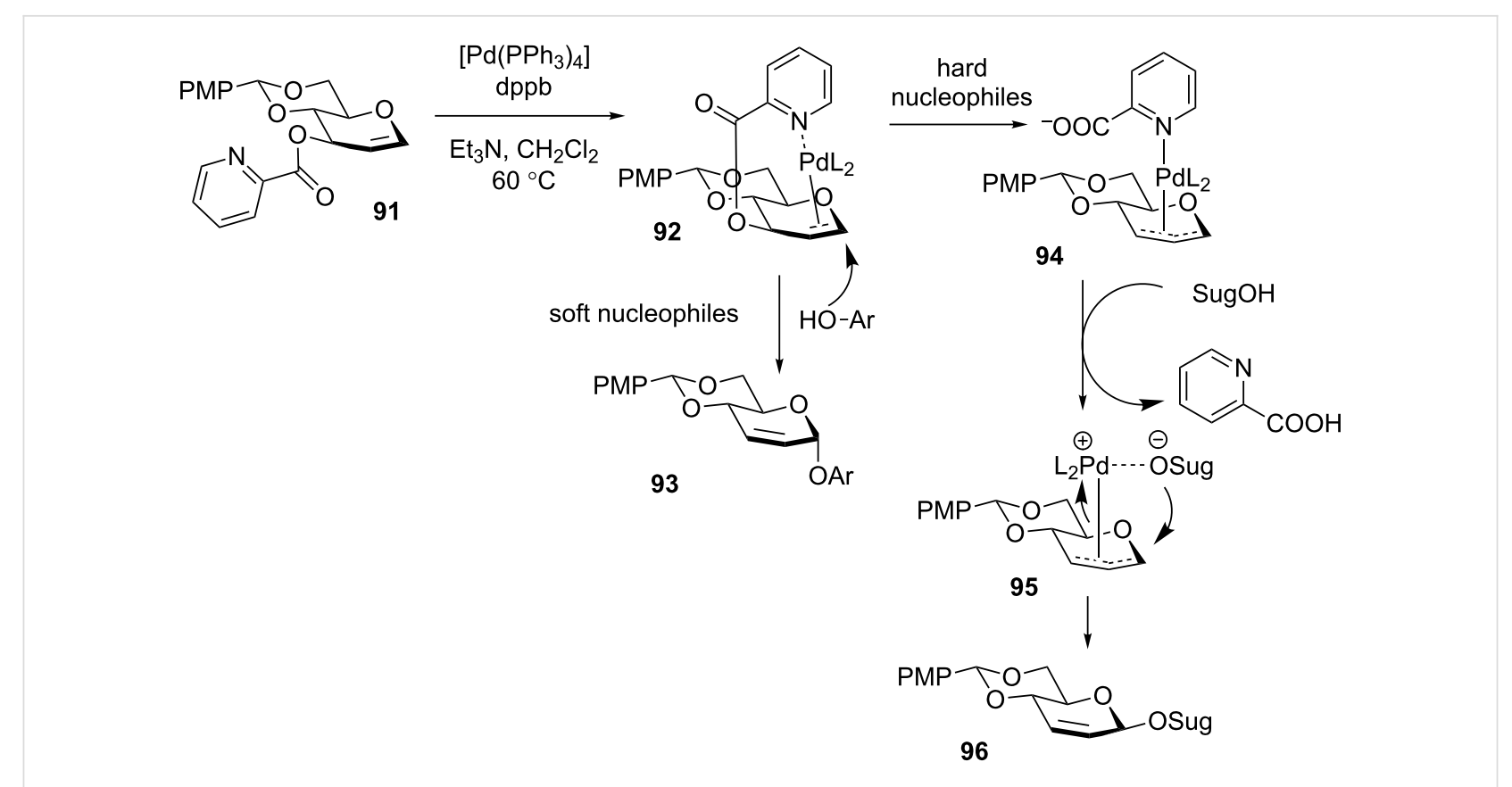

Scheme 21: Possible mechanisms to explain $\alpha$ and $\beta$ selectivity in palladium mediated IAD.

For instance, Jensen et al. developed the methyl 3,5-dinitrosalicylate (DISAL) anomeric leaving group that could be used as a platform for linking the glycosyl acceptor in place of the methyl ester [128]. Glycosylation of conjugate 97 wherein glycosyl acceptor was linked via an ester bond at the ortho-position of the DISAL leaving group of the donor gave best results under elevated temperatures. Thus, mannoside 98 was obtained in $58 \%$ yield with modest stereoselectivity (Scheme 22 ). The yields are hampered by the competing formation of the hemiacetal product 99. Crossover experiments with 1,2:5,6-di- $O$-isopropylidene- $\alpha$-D-glucofuranose acceptor showed only disaccharides resulting from the intramolecular glycosylation. However, when crossover experiments with cyclohexanol were conducted, the intermolecularly formed cyclohexyl glycoside was found to be the major product (5.2 to 1) compared to the intramolecular glycosylation product. The addition of Lewis acids helps to reduce the reaction time and the temperature required, but also increases the formation of hydrolysis products and reduces overall stereoselectivity.

Recently, Liu et al. explored the use of ortho-dihydroxyborylsubstituted benzyl thioglycosides as a delivery method for the leaving group-based intramolecular glycosylation [129]. They hypothesized that if boronic acid-derived donor $\mathbf{1 0 0}$ is activated in the presence of glycosyl acceptor 101, the boronic ester 102 would form as the key intermediate. Upon dissociation of the anomeric $\mathrm{C}-\mathrm{S}$ bond of the sulfonium intermediate 102, an oxygen nucleophile on the boronate ester would attack the $\mathrm{C}-1$ center on the opposite side resulting in $\mathbf{1 0 3}$ with good stereoselection (Scheme 23). Initial trials with 3-methylbenzyl alcohol showed good selectivity $(\alpha / \beta=4.8: 1)$ when boronic acid and NBS were employed. Control experiments with a thio-

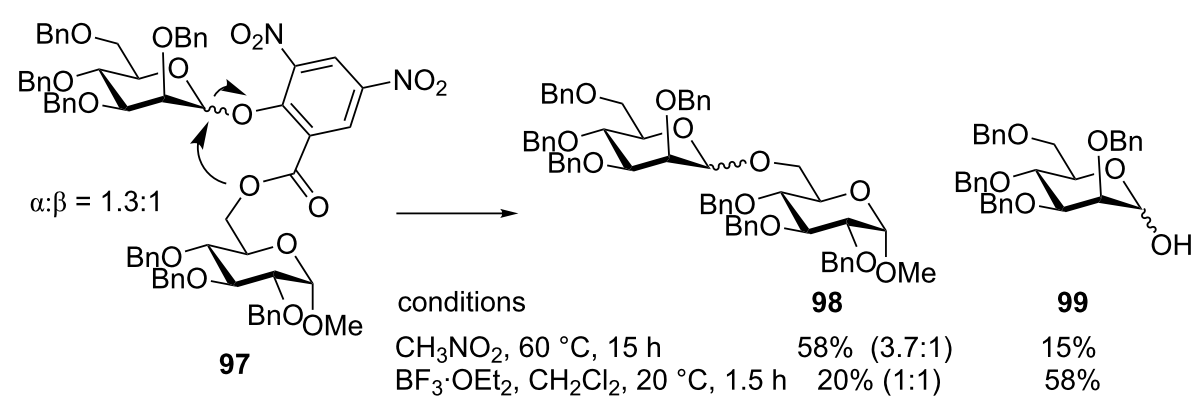




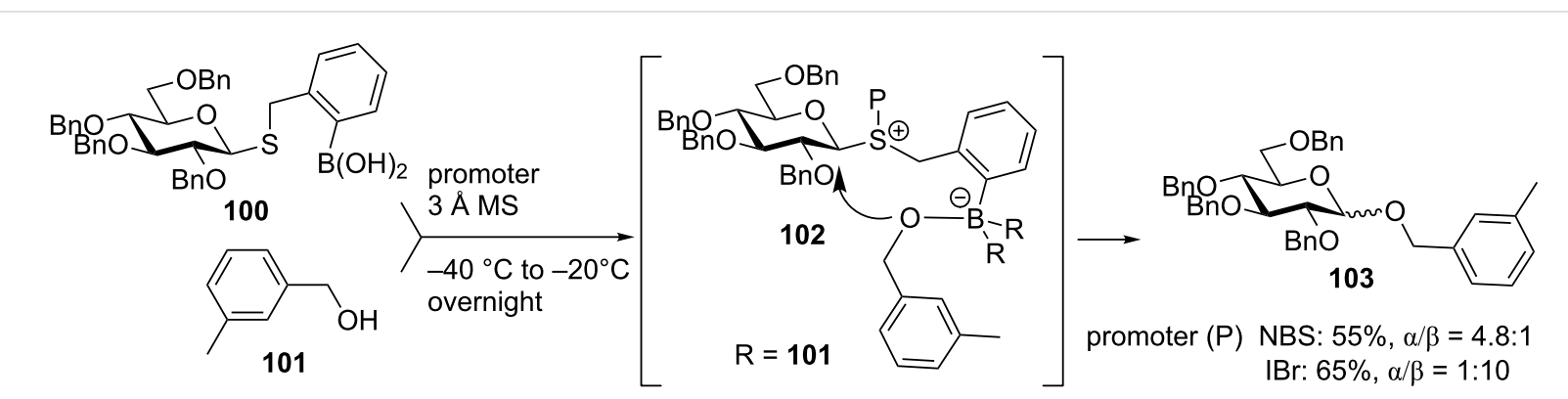

Scheme 23: Boronic acid as a directing group in the leaving group-based glycosylation method.

phenyl or a thiobenzyl leaving group showed lower stereoselectivities and a slight reduction in yields. The addition of triflic acid or silver triflate resulted in a significant reduction of stereoselectivity, so further trials were done in the absence of metal or acid reagents. Surprisingly, when IBr was used as a promoter the selectivity reversed resulting in the formation of glycoside 103 in $65 \%$ yield and high $\beta$-stereoselectivity $(\alpha / \beta=1: 10)$. The selectivity also reverses when the reaction is carried out in the presence of a coordinating solvent, for example, a similar reaction performed in acetonitrile delivers glycoside $\mathbf{1 0 3}$ in $51 \%$ yield $(\alpha / \beta=1: 4)$. When using less than three equivalents of acceptor to donor ratio, the yield drastically drops giving evidence that the borate intermediate plays an important role in the stereoselection.

\section{Conclusion}

Intramolecular glycosylation has seen dramatic advancements in the past two decades. New tethers, templates and conditions have advanced the synthesis of challenging glycosidic linkages. A more streamlined synthesis of starting materials has also made these methodologies more attractive for use in more complicated multistep syntheses. Despite the advancements made, there are still no definitive rules on why small changes may affect the stereochemical outcomes so dramatically. There is a greater need to study the underlying concepts and rules governing the use of tethers and templates and how to apply them to new systems and targets.

\section{Acknowledgements}

The authors are indebted to the National Institute of General Medical Sciences (GM111835 and GM120673) for support of their work on the development of new methods and strategies for oligosaccharide synthesis.

\section{References}

1. Cummings, R. D.; Pierce, J. M. Chem. Biol. 2014, 21, 1. doi:10.1016/j.chembiol.2013.12.010

2. Russo, L.; Cipolla, L. Chem. - Eur. J. 2016, 22, 13380. doi:10.1002/chem.201602156
3. Varki, A.; Cummings, R. D.; Esko, J. D.; Freeze, H. H.; Bertozzi, C. R.; Stanley, P.; Hart, G. W.; Etzler, M. E. Essentials of Glycobiology, 2nd ed.; CSH Laboratory Press: New York, 2009.

4. Alonzi, D. S.; Neville, D. C. A.; Lachmann, R. H.; Dwek, R. A.; Butters, T. D. Biochem. J. 2008, 409, 571. doi:10.1042/BJ20070748

5. Lebrilla, C. B.; An, H. J. Mol. BioSyst. 2009, 5, 17. doi:10.1039/B811781K

6. Adamczyk, B.; Tharmalingam, T.; Rudd, P. M. Biochim. Biophys. Acta 2012, 1280, 1347. doi:10.1016/j.bbagen.2011.12.001

7. Chaubard, J.-L.; Krishnamurthy, C.; Yi, W.; Smith, D. F.; Hsieh-Wilson, L. C. J. Am. Chem. Soc. 2012, 134, 4489. doi:10.1021/ja211312u

8. Fujitani, N.; Furukawa, J.-i.; Araki, K.; Fujioka, T.; Takegawa, Y.; Piao, J.; Nishioka, T.; Tamura, T.; Nikaido, T.; Ito, M.; Nakamura, Y.; Shinohara, Y. Proc. Natl. Acad. Sci. U. S. A. 2013, 110, 2105. doi:10.1073/pnas.1214233110

9. Ruhaak, L. R.; Miyamoto, S.; Lebrilla, C. B. Mol. Cell. Proteomics 2013, 12, 846. doi:10.1074/mcp.R112.026799

10. Zhu, X.; Schmidt, R. R. Angew. Chem., Int. Ed. 2009, 48, 1900. doi:10.1002/anie.200802036

11. McKay, M. J.; Nguyen, H. M. ACS Catal. 2012, 2, 1563. doi:10.1021/cs3002513

12. Nigudkar, S. S.; Demchenko, A. V. Chem. Sci. 2015, 6, 2687. doi:10.1039/C5SC00280J

13. Das, R.; Mukhopadhyay, B. ChemistryOpen 2016, 5, 401. doi:10.1002/open.201600043

14. Li, X.; Zhu, J. Eur. J. Org. Chem. 2016, 4724. doi:10.1002/ejoc.201600484

15. Boons, G.-J. Tetrahedron 1996, 52, 1095. doi:10.1016/0040-4020(95)00897-7

16. Fraser-Reid, B.; Madsen, R.; Campbell, A. S.; Roberts, C. S.; Merritt, R. J. In Bioorganic Chemistry: Carbohydrates; Hecht, S. M., Ed.; Oxford University Press: New York - Oxford, 1999; p 89.

17. Davis, B. G. J. Chem. Soc., Perkin Trans. 1 2000, 2137. doi:10.1039/a809774g

18. Seeberger, P. H.; Haase, W.-C. Chem. Rev. 2000, 100, 4349. doi:10.1021/cr9903104

19. Tanaka, H.; Yamada, H.; Takahashi, T. Trends Glycosci. Glycotechnol. 2007, 19, 183. doi:10.4052/tigg. 19.183

20. Seeberger, P. H. Chem. Soc. Rev. 2008, 37, 19. doi:10.1039/B511197H

21. Boltje, T. J.; Buskas, T.; Boons, G.-J. Nat. Chem. 2009, 1, 611. doi:10.1038/nchem.399 
22. Parameswar, A. R.; Demchenko, A. V. In Progress in the synthesis of complex carbohydrate chains of plant and microbial polysaccharides; Nifantiev, N. E., Ed.; Transworld Res. Network: Kerala, 2009; pp $463 \mathrm{ff}$.

23. Smoot, J. T.; Demchenko, A. V. Adv. Carbohydr. Chem. Biochem. 2009, 62, 161. doi:10.1016/S0065-2318(09)00005-5

24. Fraser-Reid, B.; López, J. C. Topics in current chemistry; Springer-Verlag: Berlin-Heidelberg, 2011; Vol. 301.

25. Kaeothip, S.; Demchenko, A. V. Carbohydr. Res. 2011, 346, 1371. doi:10.1016/j.carres.2011.05.004

26. Tanaka, K.; Fukase, K. In Solid-Phase Organic Synthesis; Toy, P. H.; Lam, Y., Eds.; John Wiley \& Sons, Inc.: Hoboken, 2012; pp 489 ff.

27. Crotti, S.; Adamo, R. Curr. Org. Synth. 2013, 10, 501. doi:10.2174/15701794113109990056

28. Yang, L.; Qin, Q.; Ye, X.-S. Asian J. Org. Chem. 2013, 2, 30. doi:10.1002/ajoc.201200136

29. Yasomanee, J. P.; Demchenko, A. V. Trends Glycosci. Glycotechnol. 2013, 25, 13. doi:10.4052/tigg.25.13

30. Bennett, C. S. Org. Biomol. Chem. 2014, 12, 1686. doi:10.1039/c3ob42343c

31. Bouhall, S. K.; Sucheck, S. J. J. Carbohydr. Chem. 2014, 33, 347. doi:10.1080/07328303.2014.931964

32. Pistorio, S. G.; Stine, K. J.; Demchenko, A. V. In Carbohydrate Chemistry: State-of-the-art and challenges for drug development; Cipolla, L., Ed.; Imperial College Press: London, 2016; pp 247 ff. doi:10.1142/9781783267200_0010

33. Muthana, S.; Cao, H.; Chen, X. Curr. Opin. Chem. Biol. 2009, 13, 573. doi:10.1016/j.cbpa.2009.09.013

34. Mydock, L. K.; Demchenko, A. V. Org. Biomol. Chem. 2010, 8, 497. doi:10.1039/B916088D

35. Crich, D. Acc. Chem. Res. 2010, 43, 1144. doi:10.1021/ar100035r

36. Frihed, T. G.; Bols, M.; Pedersen, C. M. Chem. Rev. 2015, 115, 4963. doi:10.1021/cr500434x

37. Bohé, L.; Crich, D. Carbohydr. Res. 2015, 403, 48. doi:10.1016/j.carres.2014.06.020

38. Jung, K.-H.; Müller, M.; Schmidt, R. R. Chem. Rev. 2000, 100, 4423. doi:10.1021/cr990307k

39. Madsen, J.; Bols, M. In Carbohydrates in Chemistry and Biology; Ernst, B.; Hart, G. W.; Sinay, P., Eds.; Wiley-VCH: Weinheim, New York, 2000; Vol. 1, p 449. doi:10.1002/9783527618255.ch18

40. Ziegler, T. In Handbook of Chemical Glycosylation; Demchenko, A. V., Ed.; Wiley-VCH Verlag GmbH \& Co: Weinheim, Germany, 2008; pp $469 \mathrm{ff}$.

41. Ishiwata, A.; Lee, Y. J.; Ito, Y. Org. Biomol. Chem. 2010, 8, 3596. doi:10.1039/c004281a

42. Höök, J. E.; Lindberg, B. Acta Chem. Scand. 1968, 22, 2157. doi:10.3891/acta.chem.scand.22-2157

43. Malysheva, N. N.; Torgov, V. I.; Klimov, E. M.; Kochetkov, N. K. Izv. Akad. Nauk SSSR, Ser. Khim. 1974, 2153.

44. Inaba, S.; Yamada, M.; Yoshino, T.; Ishido, Y. J. Am. Chem. Soc. 1973, 95, 2062. doi:10.1021/ja00787a084

45. Barresi, F.; Hindsgaul, O. J. Am. Chem. Soc. 1991, 113, 9376. doi:10.1021/ja00024a057

46. Kusumoto, S.; Imoto, M.; Ogiku, T.; Shiba, T. Bull. Chem. Soc. Jpn. 1986, 59, 1419. doi:10.1246/bcsj.59.1419

47. Jia, X. G. Ph.D. Thesis, University of Missouri, St. Louis, MO, 2016.

48. Fairbanks, A. J. Synlett 2003, 1945. doi:10.1055/s-2003-42056

49. Cumpstey, I. Carbohydr. Res. 2008, 343, 1553.

doi:10.1016/j.carres.2008.04.031
50. Bols, M.; Skrydstrup, T. Chem. Rev. 1995, 95, 1253. doi:10.1021/cr00037a006

51. Wakao, M.; Fukase, K.; Kusumoto, S. J. Org. Chem. 2002, 67, 8182. doi:10.1021/jo025887r

52. Ziegler, T.; Lau, R. Tetrahedron Lett. 1995, 36, 1417. doi:10.1016/0040-4039(95)00010-A

53. Lau, R.; Schüle, G.; Schwanaberg, U.; Ziegler, T. Liebigs Ann. 1995, 1745. doi:10.1002/jlac.1995199510245

54. Valverde, S.; Gómez, A. M.; Hernández, A.; Herradón, B.; López, J. C. J. Chem. Soc., Chem. Commun. 1995, 2005. doi:10.1039/C39950002005

55. Yamada, H.; Imamura, K.; Takahashi, T. Tetrahedron Lett. 1997, 38, 391. doi:10.1016/S0040-4039(96)02196-X

56. Pornsuriyasak, P.; Jia, X. G.; Kaeothip, S.; Demchenko, A. V. Org. Lett. 2016, 18, 2316. doi:10.1021/acs.orglett.6b01102

57. Lemanski, G.; Ziegler, T. Tetrahedron 2000, 56, 563. doi:10.1016/S0040-4020(99)01053-4

58. Lemanski, G.; Ziegler, T. Helv. Chim. Acta 2000, 83, 2655. doi:10.1002/1522-2675(20001004)83:10<2655::AID-HLCA2655>3.0.C $\mathrm{O} ; 2-\mathrm{U}$

59. Wakao, M.; Fukase, K.; Kusumoto, S. Synlett 1999, 1911. doi:10.1055/s-1999-2997

60. Ziegler, T.; Ritter, A.; Hürttlen, J. Tetrahedron Lett. 1997, 38, 3715. doi:10.1016/S0040-4039(97)00729-6

61. Ziegler, T.; Lemanski, G. Eur. J. Org. Chem. 1998, 163. doi:10.1002/(SICI)1099-0690(199801)1998:1<163::AID-EJOC163>3.0 .CO;2-I

62. Ziegler, T.; Lemanski, G.; Hürttlen, J. Tetrahedron Lett. 2001, 42, 569. doi:10.1016/S0040-4039(00)02032-3

63. Claude, P.; Lehmann, C.; Ziegler, T. Beilstein J. Org. Chem. 2011, 7, 1609. doi:10.3762/bjoc.7.189

64. Valverde, S.; Gómez, A. M.; López, J. C.; Herradón, B. Tetrahedron Lett. 1996, 37, 1105. doi:10.1016/0040-4039(95)02316-X

65. Valverde, S.; García, M.; Gómez, A. M.; López, J. C. Synlett 2000, 22. doi:10.1055/s-2000-6456

66. Valverde, S.; García, M.; Gómez, A. M.; López, J. C. Chem. Commun. 2000, 813. doi:10.1039/b000771o

67. Cid, M. B.; Valverde, S.; López, J. C.; Gómez, A. M. Synlett 2005, 1095. doi:10.1055/s-2005-865228

68. Huchel, U.; Schmidt, R. R. Tetrahedron Lett. 1998, 39, 7693. doi:10.1016/S0040-4039(98)01664-5

69. Müller, M.; Huchel, U.; Geyer, A.; Schmidt, R. R. J. Org. Chem. 1999, 64, 6190. doi:10.1021/jo990132e

70. Müller, M.; Schmidt, R. R. Eur. J. Org. Chem. 2001, 2055. doi:10.1002/1099-0690(200106)2001:11<2055::AID-EJOC2055>3.0.C $\mathrm{O} ; 2-\mathrm{N}$

71. Abdel-Rahman, A. A.-H.; El Ashry, E. S. H.; Schmidt, R. R. Carbohydr. Res. 2002, 337, 195. doi:10.1016/S0008-6215(01)00306-8

72. Paul, S.; Müller, M.; Schmidt, R. R. Eur. J. Org. Chem. 2003, 128. doi:10.1002/1099-0690(200301)2003:1<128::AID-EJOC128>3.0.CO;2 -S

73. Schüle, G.; Ziegler, T. Tetrahedron 1996, 52, 2925. doi:10.1016/0040-4020(95)01093-9

74. Lemanski, G.; Ziegler, T. Eur. J. Org. Chem. 2006, 2618. doi:10.1002/ejoc.200600078

75. Ogawa, T.; Takahashi, Y. Carbohydr. Res. 1985, 138, c5. doi:10.1016/0008-6215(85)85239-3

76. Tennant-Eyles, R. J.; Fairbanks, A. J.; Davis, B. G. Chem. Commun. 1999, 1037. doi:10.1039/a901916b 
77. Tennant-Eyles, R. J.; Davis, B. G.; Fairbanks, A. J. Tetrahedron: Asymmetry 2000, 11, 231. doi:10.1016/S0957-4166(99)00494-2

78. Tennant-Eyles, R. J.; Davis, B. G.; Fairbanks, A. J. Tetrahedron: Asymmetry 2003, 14, 1201. doi:10.1016/S0957-4166(03)00118-6

79. Greenwell, D. R.; Ibnouzaki, A. F.; Warriner, S. L. Angew. Chem., Int. Ed. 2002, 41, 1215. doi:10.1002/1521-3773(20020402)41:7<1215::AID-ANIE1215>3.0.CO ;2-V

80. Tiwari, V. K.; Kumar, A.; Schmidt, R. R. Eur. J. Org. Chem. 2012, 2945. doi:10.1002/ejoc.201101815

81. Kumar, A.; Geng, Y.; Schmidt, R. R. Eur. J. Org. Chem. 2012, 6846. doi:10.1002/ejoc.201201076

82. Jia, X. G.; Pornsuriyasak, P.; Demchenko, A. V. J. Org. Chem. 2016, 81, 12232. doi:10.1021/acs.joc.6b02151

83. Barresi, F.; Hindsgaul, O. Can. J. Chem. 1994, 72, 1447. doi:10.1139/v94-181

84. Stork, G.; Kim, G. J. Am. Chem. Soc. 1992, 114, 1087. doi:10.1021/ja00029a047

85. Bols, M. J. Chem. Soc., Chem. Commun. 1992, 913. doi:10.1039/C39920000913

86. Bols, M. Acta Chem. Scand. 1993, 47, 829. doi:10.3891/acta.chem.scand.47-0829

87. Bols, M. J. Chem. Soc., Chem. Commun. 1993, 791. doi:10.1039/C39930000791

88. Bols, M. Tetrahedron 1993, 49, 10049 doi:10.1016/S0040-4020(01)80200-3

89. Bols, M.; Hansen, H. C. Chem. Lett. 1994, 23, 1049. doi:10.1246/cl.1994.1049

90. Buchan, Z. A.; Bader, S. J.; Montgomery, J. Angew. Chem., Int. Ed. 2009, 48, 4840. doi:10.1002/anie.200901666

91. Walk, J. T.; Buchan, Z. A.; Montgomery, J. Chem. Sci. 2015, 6, 3448. doi:10.1039/C5SC00810G

92. Seward, C. M. P.; Cumpstey, I.; Aloui, M.; Ennis, S. C.; Redgrave, A. J.; Fairbanks, A. J. Chem. Commun. 2000, 1409. doi:10.1039/b004522p

93. Cumpstey, I.; Fairbanks, A. J.; Redgrave, A. J. Org. Lett. 2001, 3 2371. doi:10.1021/ol016175a

94. Ito, Y.; Ogawa, T. Angew. Chem., Int. Ed. Engl. 1994, 33, 1765. doi:10.1002/anie.199417651

95. Dan, A.; Ito, Y.; Ogawa, T. J. Org. Chem. 1995, 60, 4680. doi:10.1021/jo00120a002

96. Dan, A.; Lergenmüller, M.; Amano, M.; Nakahara, Y.; Ogawa, T.; Ito, Y. Chem. - Eur. J. 1998, 4, 2182. doi:10.1002/(SICI)1521-3765(19981102)4:11<2182::AID-CHEM2182> 3.0.CO;2-U

97. Ito, Y.; Ogawa, T. J. Am. Chem. Soc. 1997, 119, 5562. doi:10.1021/ja964093p

98. Pratt, M. R.; Leigh, C. D.; Bertozzi, C. R. Org. Lett. 2003, 5, 3185. doi:10.1021/ol034836t

99. Leigh, C. D.; Bertozzi, C. R. J. Org. Chem. 2008, 73, 1008. doi:10.1021/jo702032c

100. Ishiwata, A.; Munemura, Y.; Ito, Y. Eur. J. Org. Chem. 2008, 4250. doi:10.1002/ejoc.200800249

101.Yong, J. L.; Ishiwata, A.; Ito, Y. J. Am. Chem. Soc. 2008, 130, 6330. doi:10.1021/ja801574q

102. Ishiwata, A.; Ito, Y. Trends Glycosci. Glycotechnol. 2009, 21, 266. doi:10.4052/tigg.21.266
103. Ishiwata, A.; Kaeothip, S.; Takeda, Y.; Ito, Y. Angew. Chem., Int. Ed. 2014, 53, 9812. doi:10.1002/anie.201404904

104. Ishiwata, A.; Ito, Y. J. Am. Chem. Soc. 2011, 133, 2275. doi:10.1021/ja109932t

105. Ishiwata, A.; Sakurai, A.; Nishimiya, Y.; Tsuda, S.; Ito, Y. J. Am. Chem. Soc. 2011, 133, 19524. doi:10.1021/ja208528c

106. Ishiwata, A.; Ito, Y. Yuki Gosei Kagaku Kyokaishi 2012, 70, 382. doi:10.5059/yukigoseikyokaishi.70.382

107. Kaeothip, S.; Ishiwata, A.; Ito, Y. Org. Biomol. Chem. 2013, 11, 5892. doi:10.1039/c3ob41212a

108. Ishiwata, A.; Ito, Y. Glycochemical Synthesis: Strategies and Applications; John Wiley \& Sons: Hoboken, 2015; pp $361 \mathrm{ff}$.

109. Nakagawa, A.; Tanaka, M.; Hanamura, S.; Takahashi, D.; Toshima, K. Angew. Chem., Int. Ed. 2015, 54, 10935. doi:10.1002/anie.201504182

110. Tanaka, M.; Nashida, J.; Takahashi, D.; Toshima, K. Org. Lett. 2016, 18, 2288. doi:10.1021/acs.orglett.6b00926

111. Nishi, N.; Nashida, J.; Kaji, E.; Takahashi, D.; Toshima, K. Chem. Commun. 2017, 53, 3018. doi:10.1039/C7CC00269F

112.Smoot, J. T.; Pornsuriyasak, P.; Demchenko, A. V. Angew. Chem., Int. Ed. 2005, 44, 7123. doi:10.1002/anie.200502694

113.Smoot, J. T.; Demchenko, A. V. J. Org. Chem. 2008, 73, 8838. doi:10.1021/jo801551r

114. Yasomanee, J. P.; Demchenko, A. V. J. Am. Chem. Soc. 2012, 134, 20097. doi:10.1021/ja307355n

115. Yasomanee, J. P.; Demchenko, A. V. Chem. - Eur. J. 2015, 21, 6572. doi:10.1002/chem.201406589

116. Yasomanee, J. P.; Demchenko, A. V. Angew. Chem., Int. Ed. 2014, 53, 10453. doi:10.1002/anie.201405084

117.Pistorio, S. G.; Yasomanee, J. P.; Demchenko, A. V. Org. Lett. 2014, 16, 716. doi:10.1021/ol403396j

118. Yasomanee, J. P.; Parameswar, A. R.; Pornsuriyasak, P.; Rath, N. P.; Demchenko, A. V. Org. Biomol. Chem. 2016, 14, 3159. doi:10.1039/C6OB00107F

119. Kayastha, A. K.; Jia, X. G.; Yasomanee, J. P.; Demchenko, A. V. Org. Lett. 2015, 17, 4448. doi:10.1021/acs.orglett.5b02110

120.Xiang, S.; He, J.; Tan, Y. J.; Liu, X.-W. J. Org. Chem. 2014, 79, 11473. doi:10.1021/jo502078c

121.Xiang, S.; Hoang, K. L. M.; He, J.; Tan, Y. J.; Liu, X.-W. Angew. Chem., Int. Ed. 2015, 54, 604. doi:10.1002/anie.201408739

122. Behrendt, M. E.; Schmidt, R. R. Tetrahedron Lett. 1993, 34, 6733. doi:10.1016/S0040-4039(00)61687-8

123. Scheffler, G.; Schmidt, R. R. Tetrahedron Lett. 1997, 38, 2943. doi:10.1016/S0040-4039(97)00561-3

124.Scheffler, G.; Behrendt, M. E.; Schmidt, R. R. Eur. J. Org. Chem. 2000, 3527. doi:10.1002/1099-0690(200011)2000:21<3527::AID-EJOC3527>3.0.C O;2-P

125. Azumaya, I.; Kotani, M.; Ikegami, S. Synlett 2004, 959. doi:10.1055/s-2004-822885

126. Azumaya, I.; Niwa, T.; Kotani, M.; limori, T.; Ikegami, S. Tetrahedron Lett. 1999, 40, 4683. doi:10.1016/S0040-4039(99)00843-6

127.Scheffler, G.; Schmidt, R. R. J. Org. Chem. 1999, 64, 1319. doi:10.1021/jo971778e

128.Laursen, J. B.; Petersen, L.; Jensen, K. J. Org. Lett. 2001, 3, 687. doi:10.1021/ol006988j

129.Liu, X.; Zhang, B.; Gu, X.; Chen, G.; Chen, L.; Wang, X.; Xiong, B.; You, Q.-D.; Chen, Y.-L.; Shen, J. Carbohydr. Res. 2014, 398, 45. doi:10.1016/j.carres.2014.05.010 


\section{License and Terms}

This is an Open Access article under the terms of the Creative Commons Attribution License

(http://creativecommons.org/licenses/by/4.0), which permits unrestricted use, distribution, and reproduction in any medium, provided the original work is properly cited.

The license is subject to the Beilstein Journal of Organic Chemistry terms and conditions:

(http://www.beilstein-journals.org/bjoc)

The definitive version of this article is the electronic one which can be found at:

doi:10.3762/bjoc.13.201 